\title{
Firm characteristics, industry and time effects, and the cross-section of expected stock returns
}

Citation for published version (APA):

Bauer, R. M. M. J., Pavlov, B. B., \& Schotman, P. C. (2005). Firm characteristics, industry and time effects, and the cross-section of expected stock returns. METEOR, Maastricht University School of Business and Economics. LIFE Working Paper No. 008

Document status and date:

Published: 01/01/2005

Document Version:

Publisher's PDF, also known as Version of record

\section{Please check the document version of this publication:}

- A submitted manuscript is the version of the article upon submission and before peer-review. There can be important differences between the submitted version and the official published version of record.

People interested in the research are advised to contact the author for the final version of the publication, or visit the DOI to the publisher's website.

- The final author version and the galley proof are versions of the publication after peer review.

- The final published version features the final layout of the paper including the volume, issue and page numbers.

Link to publication

\footnotetext{
General rights rights.

- You may freely distribute the URL identifying the publication in the public portal. please follow below link for the End User Agreement:

www.umlib.nl/taverne-license

Take down policy

If you believe that this document breaches copyright please contact us at:

repository@maastrichtuniversity.nl

providing details and we will investigate your claim.
}

Copyright and moral rights for the publications made accessible in the public portal are retained by the authors and/or other copyright owners and it is a condition of accessing publications that users recognise and abide by the legal requirements associated with these

- Users may download and print one copy of any publication from the public portal for the purpose of private study or research.

- You may not further distribute the material or use it for any profit-making activity or commercial gain

If the publication is distributed under the terms of Article $25 \mathrm{fa}$ of the Dutch Copyright Act, indicated by the "Taverne" license above, 


\title{
Firm Characteristics, Industry and Time Effects, and the Cross-Section of EXPECTED StOck RETURNS
}

\author{
Rob Bauer \\ Limburg Institute of Financial Economics and ABP Investments \\ Borislav Pavlov \\ Limburg Institute of Financial Economics \\ Peter C. Schotman \\ Limburg Institute of Financial Economics and CEPR
}

July 2, 2005

\begin{abstract}
We construct a panel data model to explain the cross-section of individual stock returns, using monthly data for 1,144 large US firms for 1985-2002. Model specification is geared towards multiple explanatory variables, poolability across industries, alternative forecast horizons, and the effects of unobserved heterogeneity among firms. We find that combining multiple firm characteristics increases the predictive power. High expected returns are mostly related to size, cashflow-to-price and liquidity, and somewhat to earnings revisions and momentum. Diversified portfolios sorted on expected returns have moderate risk exposures and generate significant risk-adjusted returns over all horizons. Longer forecasting horizons drastically reduce portfolio turnover.
\end{abstract}

Keywords: Stock returns, Forecasting, Panel data, Industry effects

JEL codes: C23, G11

Correspondence address: Limburg Institute of Financial Economics (LIFE)

University of Maastricht, P.O. Box 616

6200 MD Maastricht, Netherlands

E-Mail: P.Schotman@berfin. unimaas.NL

Phone: (+31) 433883556

Fax: $(+31) 433884875$

\footnotetext{
* We are obliged to Magnus Dahlquist, Franz Palm, Luis Viceira, Pieter-Jelle van der Sluis, and to the participants of seminars at University of Maastricht, ABP Investments, ABN AMRO Asset Management, Stockholm Institute for Financial Research, Erasmus University Rotterdam, University of Cologne and Free University Amsterdam for useful comments, as well as to ABP Investments for providing the data, and to the participants at the $11^{\text {th }}$ International Conference on Panel Data at the Texas A\&M University. The views expressed in this paper are those of the authors and do not necessarily reflect those of ABP Investments.
} 


\section{Introduction}

A huge body of empirical research has found that various firm characteristics help to predict future stock returns. Prominent predictors are size, valuation ratios, momentum and liquidity. In addition returns are related to industries (and countries). ${ }^{1}$

The vast majority of empirical studies have studied one or two predictors in isolation. The typical statistical procedure for documenting return predictability starts with the construction of portfolios. Stocks are sorted according to a particular firm characteristic, and allocated to portfolios. If the average returns of the portfolios are significantly different, the characteristic has predictive power. With multiple characteristics the stocks are sorted along different dimensions. The best known twodimensional sort are the 25 Fama and French (1995) portfolios, sorted with respect to five size and five book-to-market categories. ${ }^{2}$ With only one or two characteristics this methodology is simple and statistically powerful.

Much less is known about the combined effect of multiple characteristics. When the number of explanatory variables grows, the portfolio formation methodology is bound to become problematic, since the number of portfolios grows exponentially with the number of characteristics. With ten different characteristics and just two categories per characteristic, we would already need $2^{10}$ different portfolios. Adding an industry effect multiplies the number of portfolios even further.

Although many effects are correlated and sometimes interact, all effects seem to contribute to the overall cross-sectional prediction of stock returns. According to Haugen (2002) it is the combination of various characteristics that leads to high expected returns: "Big, liquid, financially sound, low-risk, momentum in the market, profitable in every dimension, and becoming more profitable in every way. Yet they sell at dirt-cheap market prices." Haugen and Baker (1996) and Brennan, Chordia and Subrahmanyam (1998, BCS98) are among the few multivariate studies. Because they consider a large set of predictive variables, these articles employ a different methodology. Instead of sorting stocks in portfolios according to a particular firm characteristic, they work with cross-sectional regressions on a panel of individual

\footnotetext{
${ }^{1}$ The literature is so large that it will be impossible to cite more than a few books and empirical studies. Some book references are Bodie et al. (2002, ch. 12, 13), Cochrane (2001, ch. 20), Haugen (2002) and Campbell et al. (1997). Important empirical studies include DeBondt and Thaler (1985), Fama and French $(1992,1996,1997)$, Daniel and Titman (1997), Davis et al. (2000), Jegadeesh and Titman (1993, 2001).

${ }^{2}$ The returns of these portfolios are used in many empirical studies. Some examples are Fama and French (1996), Hodrick and Zhang (2001), Campbell and Vuolteenaho (2004).
} 
stock returns.

We extend these multivariate studies in several directions. As a first extension we consider the predictability over longer horizons. In the cross-sectional regressions of Haugen and Baker (1996) and BCS98 the dependent variable is always the monthly (excess) return. We consider the cumulative returns over one, three and six months as alternative dependent variables. Such longer holding periods are common in many studies using the portfolio sorting methodology, but do not seem to have been considered in panel regression models. If we can predict firm returns over longer periods, given a firm's current characteristics, portfolios sorted on expected returns will be much more stable in terms of turnover.

Our second extension deals with the interaction between industry effects and firm characteristics. Industries are often the first level of portfolio choice in managed portfolios. Apart from diversification arguments, the practice seems to be motivated by the considerable cross-sectional variation in expected returns across industries. Fama and French (1997) show that only a part of these cross-sectional differences can be attributed to risk factors.

Interaction between firm characteristics and industries arises in various forms. In international finance many studies have investigated the interaction between industries and countries. ${ }^{3}$ Interaction between industries and the momentum effect has been studied by Moskowitz and Grinblatt (1999) and Lewellen (2004). Both studies report evidence that industry portfolios exhibit strong momentum. In a crosssectional regression this would suggest that momentum should become much weaker, or even disappear, once we include time-varying industry effects in a panel regression model. Another example are financial firms which are often omitted because their average high debt ratios are believed to distort the relation between returns and most valuation ratios.

In our panel regressions we introduce industry effects in three different ways. First, we simply add industry dummies to the list of explanatory variables. Second, we test whether firm characteristics have identical effects across industries. These two tests examine whether we can pool intercepts and slopes in the regression analysis. Third, we consider a much more extreme alternative, where the models for each industry are completely different. Firm characteristics are only valuable for within industry prediction and we will not be able to make any between industry predictions. At the

\footnotetext{
${ }^{3}$ See, for example, Heston and Rouwenhorst (1994) and Cavaglia et al. (2000).
} 
level of portfolio sorts, it would mean that firms are first sorted into industries, using firm characteristics to find the best stocks within each industry.

Our third extension is the inclusion of individual effects $\left(\mu_{i}\right)$. This introduces even more heterogeneity than the industry effects. With individual effects each stock has its own unconditional expected return, irrespective of its average characteristics. We consider individual effects for two reasons. First, the amount of unobserved crosssectional heterogeneity in average stock returns $\left(\operatorname{Var}\left(\mu_{i}\right)\right)$ is a measure of the fit of the cross-section of expected returns. Important unobserved heterogeneity at the level of individual firms is an indication for missing predictive variables. Second, if the individual effects are correlated with one or more characteristics, they will affect estimates of the slope parameters in the panel. Conrad and Kaul (1998) and Jegadeesh and Titman (2002) provide examples of the interaction between individual effects and momentum. Both studies estimate how much of momentum profits can be explained by the cross-sectional variation of the unconditional expected returns $\left(\operatorname{Var}\left(\mu_{i}\right)\right)$. In this case there exists an obvious correlation between past returns and unconditional average returns. In our panel regressions we formally test whether firm characteristics have significantly different effects in models with and without individual effects.

Three further issues are worth discussing in this introduction: data snooping, econometric tests and risk adjustment. Our predictive variables (size, value, momentum and liquidity) have featured in many previous studies. These variables have been subjected to predictability tests for different countries and sample periods. They also seem to create anomalies, as their effects cannot be fully captured by risk adjustment. As such it is not surprising that many of them show up "significantly" in our multivariate panel regressions. To mitigate the data snooping we use a data set that has been used less frequently. Our panel contains 1,144 US stocks over a period of 17 years that are followed by Morgan Stanley Capital International (MSCI). This data set defines the investable universe for many institutional investors. Compared to other common data sets, the MSCI panel contains fewer small cap stocks.

Most challenging for statistical testing in panels of individual stocks are the contemporaneous covariances among the errors. Even after correcting for a limited number of risk factors, much cross correlation remains. Estimating a full cross-sectional covariance matrix will be infeasible given the large number of individual stocks and the short time series history of many stocks. To get around this problem many studies have used the Fama and MacBeth (1973) estimator, in which inference is based on a time series of cross-sectional regressions. This estimator will not be applicable, 
however, in our panel regressions when firm specific individual effects are introduced. These effects are specific for each stock and cannot be identified from a cross-sectional regression. We therefore use a single least squares regression in a two-way fixed effects panel data model. For the standard errors we rely on an estimator of the standard errors proposed by Driscoll and Kraay (1998), which is consistent in the presence of arbitrary cross-sectional correlation and heteroskedasticity. The third econometric issue is the model selection. The number of intercept parameters, related to individual and time effects, grows as the panel dimensions increase. This implies that restrictions imposed on these parameters cannot be tested reliably with standard test statistics. We therefore select models using the Schwartz information criterion.

From the panel models we obtain the expected returns for each stock in every time period. Sorting directly on the expected returns we can compare the typical characteristics of portfolios with high and low average returns. After sorting stocks on expected returns, we regress the portfolio returns on all well-known risk factors to examine how much of the variation in the expected returns can be attributed to differences in risk.

We find that firm characteristics have predictive power and interact with industry effects. Multivariate prediction of expected stock returns is superior to univariate prediction. Construction of long-short portfolios, based on our multivariate models, shows that long and short portfolios have very distinctive characteristics. Risk factor analysis shows that the portfolios earn substantial abnormal returns with significant exposure to size, low exposure to market risk and momentum, and no exposure to value. The strongest results are obtained when we increase the forecasting horizon. This does not deteriorate returns, only marginally changes the risk exposure, and dramatically reduces portfolio turnover. Trading strategies become very stable over time. Only about five percent of the top 30\% highest expected return stocks differ from month to month.

The remainder of the paper is organized as follows. Section 2 discusses the specification of the panel model, the model selection criterion and hypothesis testing. Section 3 describes the data and provides univariate analysis of the predictive power of firm characteristics. Section 4 reports results from the specification tests for panel data models for forecasting of stock returns. Section 5 considers the implications for portfolios that are constructed by sorting stocks on expected returns. Section 6 concludes. 


\section{Methods}

Our interest is in predicting returns $y_{i t}$ of individual stocks using a vector of firm characteristics $x_{i t}$. The basic model we consider is a two-way error component panel,

$$
y_{i t}=\mu_{i}+\lambda_{t}+x_{i t}^{\prime} \beta+e_{i t}
$$

where $\mu_{i}$ is a stock specific effect, $\lambda_{t}$ is a time effect, $\beta$ is a $K$-vector of parameters, and $e_{i t}$ is an error term. The errors have a zero mean and are assumed to be uncorrelated with the regressors, i.e. $\mathrm{E}\left[x_{i t} e_{i t}\right]=0$. In each period $t$ complete data for returns and characteristics are observed for $N_{t}$ firms. Return data are observed for $T$ months. A total of $N$ different firms are observed with $T_{i}$ observations for firm $i$. The total number of data points is $n=\sum_{t} N_{t}=\sum_{i} T_{i}$.

The empirical literature on predicting stock returns usually considers holding periods of varying lengths. For example, in testing momentum strategies, the usual holding period ranges from one to six months. Sorting on book-to-market often takes place once a year, and the resulting portfolios are held for one year. We consider panel regressions for returns over holding periods from one to six months. For these regressions the dependent variable $y_{i t}$ is the cumulative return over a period of $J$ months, following month $t$,

$$
y_{i, t+J}^{(J)}=\prod_{j=1}^{J}\left(1+R_{i, t+j}\right)-1,
$$

with $R_{i t}$ the single period returns. Though the explanatory variables $x_{i t}$ remain the same for all horizons, different values of $J$ give rise to different dependent variables, different parameters and different errors. To keep notation simple we will keep the generic notation of equation (1) with $y_{i t}$ instead of the convoluted expression $y_{i, t+J}^{(J)}$. When returns are measured over a horizon longer than the sampling interval, e.g. three month returns, the panel regression uses overlapping data and we must take the resulting autocorrelation in the errors into account. The firm characteristics $x_{i t}$ are observed in month $t$. Further details about estimation and inference are discussed in the relevant sections below.

We consider four types of firm characteristics: size, measured as the logarithm of market value; various valuation ratios like earnings-to-price and book-to-price; momentum, measured as various functions of past returns; and liquidity, measured as the logarithm of trading volume in previous months. 


\subsection{Time effects}

The purpose of the model is to predict the cross-section of expected stock returns. We assume that the time effects $\lambda_{t}$ are fully unrestricted fixed effects. One way to interpret these effects is that $\lambda_{t}$ is an unobserved common factor against which all stocks have a beta equal to one. Since $\lambda_{t}$ is an unrestricted parameter, we cannot predict this common factor with information at $t-1$. Absolute forecasts cannot be made with this model. The common factor cancels out, however, when making relative predictions of cross-sectional return differences $y_{i t}-y_{j t}$.

Estimating the panel with time effects implies that all variables are taken in deviation from their cross-sectional mean. For a variable like earnings-to-price $(E P)$ this implies that we only consider the cross-sectional effect whether firms with high $E P$ ratios tend to generate higher returns than firms with low EP ratios. The time effect $\lambda_{t}$ accounts for a possible effect of a historically low EP ratio on all returns.

The time effects are a crude way to adjust for systematic risk. Since not all beta's are equal to one, and returns are generated by multiple factors, some cross-sectional covariance among the returns will remain. Still, time effects take out a large common noise component from the returns, and thus reduce the cross-sectional correlation of the errors, which in turn will enhance estimation efficiency. Because of the large crosssectional dimension, we do not attempt to explicitly specify the full cross-sectional covariance structure of the errors $e_{i t}$ any further.

\section{$2.2 \quad$ Individual Effects}

The second element in the specification of equation (1) are the individual effects $\mu_{i}$. They serve as a diagnostic, as one would hope that they can be omitted. With individual effects in the model the relative returns of stocks $i$ and $j$ depend on the difference $\mu_{i}-\mu_{j}$. Expected returns on stocks $i$ and $j$ differ for some unobserved reason. In searching for stocks with high expected returns, we would need to take into account the estimates of $\mu_{i}$ for $i=1, \ldots, N$. These are likely to be poorly estimated, as information on them can only come from the time series dimension of the data. Firms without a long history will have especially poorly determined individual effects. Furthermore, individual firm returns are very noisy - that is exactly what usually motivates portfolio formation - and the forecasting performance of the model will be negatively affected by the noisy estimates of $\mu_{i}$.

On the other hand, the cross-sectional variation in $\mu_{i}$ does tell us a lot about 
the unmodeled systematic cross-sectional variation in the data, and thus about the goodness of fit. When the individual effects $\mu_{i}$ make a significant contribution to the cross-sectional variation of expected returns, there is much scope for improvement of the model. The larger the variance of $\mu_{i}$, the more scope for improvement.

If individual effects are correlated with the average characteristics of a firm, then omitting individual effects will affect the estimates of the slope parameters $\beta$. Such a correlation arises for example with the momentum effect. Since momentum is a function of lagged returns of stock $i$, it will be positively correlated with $\mu_{i}$. The larger the dispersion in $\mu_{i}$, the bigger the effect on the momentum coefficients in $\beta$, and the more likely to wrongly conclude that momentum is significant when instead individual effects should have been included. Conrad and Kaul (1998) and Jegadeesh and Titman (2002) both estimate how much of the momentum profits can be explained by the cross-sectional variation of the unconditional expected returns (the cross-sectional variance of $\left.\mu_{i}\right)$. Contrary to Conrad and Kaul (1998), Jegadeesh and Titman (2002) conclude that $\operatorname{Var}\left(\mu_{i}\right)$ is small and negligible relative to the potential gains of a momentum trading strategy. They also conclude, however, that it is difficult to estimate $\operatorname{Var}\left(\mu_{i}\right)$ because many stocks have short time series histories, which precludes precise estimation of the individual $\mu_{i}$. Instead of estimating $\operatorname{Var}\left(\mu_{i}\right)$ we consider a direct Hausman type of test on the difference of regression parameters in models with and without individual effects. Details on the test are provided in section 2.4.

Individual effects can also interfere with other firm characteristics. Some firms can have a high book-to-price ratio on average without generating especially high returns. The book-to-price effect might be much larger for a firm for which the bookto-price ratio has increased recently because something unusual has happened, like a sudden drop in its stock price. For these firms we might expect an increase in future returns, either because of an increase in the risk of that stock or due to an overreaction causing temporary undervaluation. If this hypothesis is true, we would expect a bigger coefficient of the book-to-price variable in a model with individual effects compared to a model with a pooled intercept. If the book-to-price coefficient is significantly different in the two models, this has implications for portfolio trading strategies. In sorting stocks on their book-to-price ratio, it would be more effective to sort on the book-to-price in deviation of its historical mean.

Because of the possible interaction between the individual effects and the explanatory variables, we will treat the $\mu_{i}$ 's as fixed effects and not as random effects. From the panel data literature it is known that random effects estimation is inconsistent if 
$\mu_{i}$ and $x_{i t}$ are correlated.

\subsection{Industry effects}

Industry effects are introduced in three ways. First we introduce a vector of $L$ industry specific time effects $\lambda_{\ell t}$ instead of the single time effect $\lambda_{t}$. Equation (1) is generalized to

$$
y_{i t}=\mu_{i}+\sum_{\ell=1}^{L} D_{i \ell} \lambda_{\ell t}+x_{i t}^{\prime} \beta+e_{i t} .
$$

As for the single time effect, we will assume that all industry specific $\lambda_{\ell t}$ are unrestricted parameters. They can be interpreted as industry risk factors. A direct consequence is that cross-sectional predictions can be made only within the same industry. For firms $i$ and $j$ that belong to separate industries $k$ and $\ell$ the relative return $y_{i t}-y_{j t}$ involves a term $D_{i k} \lambda_{k t}-D_{j \ell} \lambda_{\ell t}$, which is unknown at time $t-1$. Trading strategies based on a panel model with industry specific time effects imply picking the best stocks within each industry in every period.

Industry specific time effects can change the estimates of some of the slope parameters in $\beta$. A typical example is the Moskowitz and Grinblatt (1999) hypothesis that momentum is actually an industry effect. They find that momentum does not help predict the relative returns of individual firms, but rather the relative performance of entire industries. The predictive power of momentum should decrease once we correct for industry-wide effects. If the hypothesis of Moskowitz and Grinblatt (1999) is correct, and we estimate the panel with industry specific time effects, we should expect that the momentum parameters will become smaller and less significant. Otherwise we would be able to predict the relative returns within the same industry using individual firm momentum.

Second, industry effects could be useful as a restriction on the individual effects,

$$
\mu_{i}=\sum_{\ell=1}^{L} D_{i \ell} \tau_{\ell}
$$

where $\tau_{\ell}$ is a fixed industry specific effect. Industry specific intercepts are less restrictive than a single pooled intercept, and yet allow for considerable cross-sectional heterogeneity. In this sense industry intercepts can be a good alternative to individual effects. Whereas individual effects can be difficult to estimate, pooling the intercepts for all firms within the same industry will be more precise. The parameters $\tau_{\ell}$ can 
explain the average differences in returns among industries. Due to lack of identification a model cannot contain industry specific time effects $\lambda_{\ell t}$ and industry specific intercepts $\tau_{\ell}$ at the same time.

The third way of accounting for industry effects is by allowing separate slope parameters $\beta_{\ell}$ for each industry. The most general specification of the panel model replaces equation (1) by

$$
y_{i t}=\mu_{i}+\sum_{\ell=1}^{L} D_{i \ell}\left(\lambda_{\ell t}+x_{i t}^{\prime} \beta_{\ell}\right)+e_{i t} .
$$

In this model industries are completely separated. Intermediate cases arise with either separate slopes and pooled time effects, or with individual effects restricted to industry intercepts. Without any pooling on either $\lambda_{\ell t}$ or $\beta_{\ell}$ we have $L$ different panel data models. The three ways to control for industry effects can be introduced separately, or can be combined. Combining industry specific intercepts and time effects would lead to overidentification.

\subsection{Estimation and testing}

Estimation and testing are affected by a number of issues that are typical for panels with stock returns at the individual firm level. First, the panel is inherently unbalanced since stocks come, merge and go. Second, both $N$ and $T$ are large. In our application the cross-sectional dimension $N_{t}$ ranges between 204 and 940 companies, while $T=200$ months. Third, the errors $e_{i t}$ are likely to be strongly cross-sectionally correlated even after including time effects, whether pooled $\lambda_{t}$ or industry specific $\lambda_{\ell t}$. Because of the large cross-sectional dimension, it will be infeasible, however, to estimate all elements $\mathrm{E}\left[e_{i t} e_{j t}\right]$ of the $(N \times N)$ cross-sectional error covariance matrix. As a consequence we cannot derive an optimal efficient estimator. Instead of the infeasible optimal GMM estimator we estimate the parameters by OLS. For the standard errors of $\hat{\beta}$ we will use an estimator that is consistent in $T$, but not in $N$.

To discuss econometric issues we write the model in matrix notation. We ignore the unbalanced nature of the panel to keep the notation simple. ${ }^{4}$ The various specifications regarding the pooling of industries can all be subsumed within the following

\footnotetext{
${ }^{4}$ The intricate computational details for an unbalanced panel with two-way effects can be found in Wansbeek and Kapteyn (1989) and Baltagi (2001, ch. 9), but are not essential for the issues we discuss below.
} 
generic specification of the panel,

$$
y_{t}=\mu+D f_{t}+Z_{t} \delta+e_{t}
$$

where we use the following vector notation:

$y_{t}: N$-vector of returns in period $t$;

$D:(N \times L)$ matrix of industry dummies indicating which industry each firm belongs to, $D \iota_{L}=\iota_{N}$, where $\iota_{L}$ is a vector of ones of length $L$;

$f_{t}: L$-vector of industry time effects $\lambda_{\ell t}$;

$Z_{t}:(N \times M)$ matrix of explanatory variables. The number of regressors $M$ depends on the industry pooling assumptions;

$\delta: M$-vector of coefficients;

$e_{t}: N$-vector of errors.

Some important special cases are tabulated below:

Pooled time effects : $f_{t}=\iota_{L} \lambda_{t}$, with $\lambda_{t}$ a scalar, so that $D f_{t}=\iota_{N} \lambda_{t}$;

Pooled slopes $\quad: M=K ; Z_{t}=X_{t}$, the $(N \times K)$ matrix with rows equal to the predictor variables $x_{i t}^{\prime}$; and $\delta=\beta$;

Industry slopes $\quad: Z_{t}$ contains $M=K L$ explanatory variables with rows $z_{i t}^{\prime}=D_{i} \otimes x_{i t}^{\prime} ;$ and $\delta$ stacks all industry specific $\beta_{\ell}$;

Industry intercepts : $\mu=D \tau ; Z_{t}=X_{t}$; and $\delta=\beta$, where $\tau$ is the $L$-vector of industry intercepts.

Identification of the intercepts requires a normalization of either $\lambda_{t}$ or $\mu_{i}$ in models where both are included. The normalization is arbitrary as we are mainly interested in the slope parameters $\delta$.

Industry specific time effects are eliminated by premultiplying equation (6) by

$$
Q=I-D\left(D^{\prime} D\right)^{-1} D^{\prime}
$$

which takes all returns and regressors in deviation of their cross-sectional industry average. Both individual effects and industry specific time effects are eliminated by the transformation of a two-way fixed effects panel

$$
\tilde{y}_{i t}=y_{i t}-\bar{y}_{\ell, t}-\bar{y}_{i}+\bar{y}_{\ell}
$$

where $\bar{y}_{\ell, t}$ is the industry average of industry $\ell$ in period $t, \bar{y}_{i}$ is the time series average of firm $i$, and $\bar{y}_{\ell}$ is the time series average of $\bar{y}_{\ell, t}$. All explanatory variables 
are transformed analogously. With a pooled time effect all variables are taken in deviation of the cross-sectional average for all firms.

After eliminating the fixed effects $\mu_{i}$ and/or $\lambda_{t}$, the OLS estimator of the slopes is

$$
\hat{\delta}=\left(\frac{1}{T} \sum_{t=1}^{T} \tilde{Z}_{t}^{\prime} \tilde{Z}_{t}\right)^{-1}\left(\frac{1}{T} \sum_{t=1}^{T} \tilde{Z}_{t}^{\prime} \tilde{y}_{t}\right) .
$$

The number of elements in $\hat{\delta}$ is small relative to the panel dimensions $N$ and $T$. Due to the cross-sectional correlation, the cross-sectional dimension $N$ is of little use for inference. We use a robust estimator of the covariance matrix of $\hat{\delta}$ proposed by Driscoll and Kraay (1998) that is consistent in $T$, independent of $N$. As in Driscoll and Kraay (1998) we use that

$$
\operatorname{Var}(\sqrt{T}(\hat{\delta}-\delta))=V_{Z Z}^{-1} S V_{Z Z}^{-1},
$$

where $V_{Z Z}=\operatorname{plim} \frac{1}{T} \sum_{t} \tilde{Z}_{t}^{\prime} \tilde{Z}_{t}$ and

$$
S=N E\left[\sum_{s=-\infty}^{\infty} h_{t-s} h_{t}^{\prime}\right]
$$

with the time series of $M$-vectors $h_{t}$ defined as

$$
h_{t}=\frac{1}{\sqrt{N_{t}}} \tilde{Z}_{t}^{\prime} \tilde{e}_{t}
$$

We estimate $S$ using the Newey-West weights on the first $m$ autocorrelations,

$$
\hat{S}=\frac{N}{T} \sum_{s=-m}^{m}\left(1-\frac{|s|}{m+1}\right) \sum_{t=1}^{T} \hat{h}_{t-s} \hat{h}_{t}^{\prime}
$$

where $\hat{h}_{t}$ uses the estimated residuals $\hat{e}_{t}$. The autocorrelation lag $(m)$ in the NeweyWest estimator depends on the forecast horizon of the model and is at least as big as the number of months over which the cumulative returns $y_{i t}$ are computed. The matrix $V_{Z Z}$ is replaced by its empirical finite sample counterpart.

Other panel studies, for example Haugen and Baker (1996) and BCS98, use the Fama and MacBeth (1973) coefficient estimator. It is defined as the time series average of a series of $T$ cross-sectional regressions, ignoring the individual effects,

$$
\begin{aligned}
\hat{\delta}_{F M} & =\frac{1}{T} \sum_{t=1}^{T} \hat{\delta}_{t} \\
\hat{\delta}_{t} & =\left(\tilde{Z}_{t}^{\prime} \tilde{Z}_{t}\right)^{-1} \tilde{Z}_{t}^{\prime} \tilde{y}_{t} .
\end{aligned}
$$


For comparison, the standard OLS estimator of the coefficient vector $\delta$ in a model without individual effects is a matrix weighted average of the Fama-MacBeth crosssectional $\hat{\delta}_{t}$,

$$
\hat{\delta}_{O L S}=\left(\sum_{t=1}^{T} \tilde{Z}_{t}^{\prime} \tilde{Z}_{t}\right)^{-1} \sum_{t=1}^{T} \tilde{Z}_{t}^{\prime} \tilde{Z}_{t} \hat{\delta}_{t} .
$$

The OLS estimator gives equal weight to each data point instead of equal weight to each time period. This means that periods with much cross-sectional dispersion in the firm characteristics will be more influential. Likewise, months with larger crosssections will be more influential for estimating $\delta$. Since the number of stocks in our panel grows over time, the more recent periods have a relatively large weight in the OLS estimator compared to the Fama-MacBeth estimator. Without individual effects both estimators are consistent, but not necessarily efficient. In a two-way panel with individual effects the Fama-MacBeth estimator suffers from omitted variables bias if individual effects are correlated with the explanatory variables.

A further complication are the lagged returns among the predictive variables. It is well-known that lagged dependent variables cause biases in dynamic panel data models. The bias disappears when $T$ is large, as we assume, or if the individual effects $\mu_{i}$ can be omitted.

Prior to inference on the model coefficients we must decide on the inclusion of individual effects and (industry specific) time effects. The number of individual and time effects grows as $N$ or $T$ becomes large. This implies that restrictions imposed on the individual or time effects cannot be tested reliably with standard test statistics. For model selection we therefore rely on the Schwartz information criterion $(S C)$,

$$
S C=\ln s^{2}+\frac{k}{n} \ln n,
$$

where $s^{2}$ is the residual sum of squares of the estimated model, $n$ is the total number of data points in the panel and $k$ is the total number of parameters including all individual and time effects. ${ }^{5}$ In the application we have more than 1,100 firms and

\footnotetext{
${ }^{5}$ It is unknown, however, whether $S C$ is a consistent model selection criterion in this panel. Bai and $\mathrm{Ng}$ (2002) provide some theoretical guidance on this question. Like us they consider a panel with large $N$ and $T$. Their assumptions on the error terms are also appropriate for our panel. Most critical is the bound on the cross-sectional covariance stating that the sum over all $\mathrm{E}\left[e_{i t} e_{j t}\right]$ is at most of order $N$. They consider a factor model for which the number of parameters is of order $M(T+N)$ with $M$ denoting the number of unobserved factors. Their interest is in estimating $M$. In our model the number of parameters is of order $N+L T$, and our interest is whether we can exclude $N$ of them that represent individual firm effects. A further interest is whether we can exclude $(L-1) T$ parameters that represent industry specific time effects.
} 
200 months of data. After deletion of missing values more than 90,000 data points are available. With these values of $N, T$ and $n$, and $K$ fixed and small, the $S C$ will select a model with individual effects if the residual sum of squares is reduced by $14 \%$. For comparison, the classical $F$-test will already be significant at the $1 \%$ level if the sum of squared residuals falls by less than $1 \%$. The critical value of the $F$-test is misleading though, since the errors in equation (1) are very likely to be cross-sectionally correlated, even after allowing for time effects $\lambda_{\ell t}$. The Schwartz criterion will be more conservative than the $F$-test.

Incorrectly omitting the individual effects can have an effect on the slope parameters $\delta$, whenever $\mu_{i}$ and $x_{i t}$ are correlated. We use a version of the Hausman test to check if estimates of $\delta$ differ significantly between a model with individual effects and a model with either a single intercept or industry specific intercepts. The fixed effect estimator of a model with individual effects is denoted $\hat{\delta}_{I}$. Restricting the individual effects to $\mu=D \tau$ (or $\mu=0$ ) leads to the estimator $\hat{\delta}_{P}$. Under the null that $\mu_{i}$ is not correlated with $x_{i t}$ both estimators are consistent, with $\hat{\delta}_{P}$ likely to be more efficient, as it omits the unnecessary individual effects. Under the alternative, $\hat{\delta}_{P}$ will be inconsistent. Therefore the difference $\hat{\delta}_{I}-\hat{\delta}_{P}$ can tell us if individual effects have an effect on the slope coefficients $\delta$.

From the expression of the standard errors in equation (10) we know that we can write the difference between the two estimators as

$$
\sqrt{T}\left(\hat{\delta}_{I}-\hat{\delta}_{P}\right)=\frac{1}{\sqrt{T}} \sum_{t}\left(V_{I I}^{-1} h_{I t}-V_{P P}^{-1} h_{P t}\right)=\frac{1}{\sqrt{T}} \sum_{t} g_{t}
$$

where $V_{I I}$ and $V_{P P}$ are the relevant matrices corresponding to the general $V_{Z Z}$ in equation (10), $h_{I t}$ and $h_{P t}$ the relevant time series related to $h_{t}$ in equation (12), and $g_{t}$ is defined as

$$
g_{t}=V_{I I}^{-1} h_{I t}-V_{P P}^{-1} h_{P t} .
$$

Having constructed $g_{t}$, the covariance matrix of $\sqrt{T}\left(\hat{\delta}_{I}-\hat{\delta}_{P}\right)$ follows as

$$
D=\frac{1}{T} \sum_{s=-m}^{m}\left(1-\frac{|s|}{m+1}\right) \sum_{t=1}^{T} \hat{g}_{t-s} \hat{g}_{t}^{\prime},
$$

We use this covariance matrix to compute the Hausman test statistic

$$
W_{H}=T\left(\hat{\delta}_{I}-\hat{\delta}_{P}\right)^{\prime} D^{-1}\left(\hat{\delta}_{I}-\hat{\delta}_{P}\right)
$$




\section{Data and univariate analysis}

The section describes the raw data and how they are transformed to regressors in the panel data models. Results from univariate analysis of the predictive power of firm characteristics are reported as well.

\subsection{Explanatory variables}

Our data set is the Morgan Stanley Capital International (MSCI) US data universe. It covers the investable universe for most institutional investors. As such it contains relatively few small cap stocks. We include all US firms explicitly followed by MSCI. Some of them are the constituents of the well-known published MSCI US index. Others are followed by MSCI because of their size or relevance. To minimize the potential back filling bias we include companies in the data set only when investors were able to obtain the information provided by MSCI in real time. The MSCI index covers about $70 \%$ of the US stock market capitalization. The sample period ranges from November 1984 until June 2002. The raw data set contains 1,243 large companies.

We have chosen eleven regressors that have been widely used over the last fifteen years, have proved to contribute to the prediction of stock returns, and are likely to capture different facets of a company. The eleven explanatory variables are classified into four groups: size, valuation ratios, momentum and liquidity.

\subsubsection{Size}

Size $(M V)$ is defined as the logarithm of the market capitalization of firm $i$ in month t. The relation between size and stock returns is known since the early 1980's. It appears in many studies, like e.g. Fama and French (1992), Haugen and Baker (1996), Daniel and Titman (1997) and BCS98.

\subsubsection{Valuation ratios}

We include the ratios book-to-price $(B P)$, earnings-to-price $(E P)$, dividends-to-price $(D P)$, cash flow-to-price $(C P)$ and sales-to-price $(S P)$. A few of the many studies analysing the link between valuation ratios and stock return are Rosenberg et al. (1985), Fama and French (1992), Lakonishok et al. (1994), and Daniel and Titman (1997). Cochrane (2001) discusses the use of valuation ratios like $S P$ and $D P$ for the 
prediction of stock returns. Vuolteenaho (2002) finds that cashflow news influences stock returns.

\subsubsection{Momentum}

We include two types of momentum variables. Short-term price momentum is defined as the cumulative return over the last six months (R1-6), and long-term price momentum is defined as the cumulative return over the six months prior to the last six months $(R 7-12)$. As common, the variable $(R 1-6)$ is lagged by an additional month to avoid any spurious relation between the current month return and the future month return caused by bid-ask spread effects and thin trading. The second type of momentum is earnings momentum (analyst earnings revisions), denoted by CFY1. It reflects the expectation revisions of financial analysts about the next year's earnings of the stock, and is computed as the number of positive revisions minus the number of negative revisions, divided by the total number of revisions. The original source of this data is I/B/E/S. Momentum variables are used in Jegadeesh and Titman (1993) and Rouwenhorst (1998). Chan et al. (1996) discuss both earnings momentum and price momentum. Frankel and Lee (1998) focus on earnings momentum.

\subsubsection{Liquidity}

We use two liquidity variables. The first one $(V O L)$ is the log of monthly turnover volume. The second variable $(52 \mathrm{~W})$ is the log of average turnover volume for the last 52 weeks. Stoll (1978), among others, finds that volume is the most important determinant of the bid-ask spread, while Brennan and Subrahmanyam (1995) find that it is a basic determinant of liquidity. Koski and Michaely (2000) discuss the relation between liquidity and stock prices and returns. BCS98 recommend defining separate liquidity variables for NYSE and NASDAQ stocks, since trading volume is measured differently between NYSE and NASDAQ. On the other hand the stocks traded at NASDAQ are concentrated in small number of industries. Since our general model in equation (5) includes industry specific coefficients and time effects, we do not split the liquidity variables. 


\subsubsection{Industries}

Each company belongs to a specific industry. ${ }^{6}$ The total number of industries is 22 . Various studies investigate the interaction between firm characteristics and industries, and the impact of this relation on the cross-sectional stock return volatility. Dempsey et al. (1993) find a significant relation between industry and dividend payout, and thus between industry and DP. Moskowitz and Grinblatt (1999) argue that industry momentum strategies outperform momentum strategies after controlling for firm characteristics. Baca et al. (2000) emphasize the general importance of industry effects in the equity markets. Fama and French (1997) focus on the industry costs of equity.

\subsection{Summary statistics}

The numbers of companies per industry in the data set are reported in Table 1. Some industries contain only a few firms, indicating that we should be careful in interpreting their industry specific parameters. ${ }^{7}$

Panel A of Table 2 reports descriptive statistics of the raw data set of 1,243 firms. Some firm characteristics like the valuation ratios have extreme outliers. For the econometric analysis we delete all data points that contain incomplete or missing data. This reduces the data set to 1,144 companies and 93,482 data points, which amounts to $88.6 \%$ of the number of data points for which the monthly return (RET) is observed. ${ }^{8}$ The outliers are less extreme compared to the ones in panel A due to the deletion of the incomplete data. After inspection of the worst outliers we concluded that they were not due to deficiencies of the data. Since outliers in the valuation ratios have a strong influence on the regression results, we trimmed all valuation ratio outliers to the lower and upper $1 \%$ tail of the distribution. Descriptive statistics of the final data set data are reported in panel B of Table 2.

\footnotetext{
${ }^{6}$ We use the MSCI industry classification that was used before April 1999. In April 1999 MSCI and S\&P 500 introduced the Global Industry Classification System (GICS). Using the new industry classification in all periods would result in a look ahead bias, while using it only after April 1999 would lead to unreliable results due to the short time series April 1999 - June 2002.

7 These industries are Power Producers, Data Processing and Computer Services. The low number of firms in the last two industries can be explained by the high number of firms in the industry Technology Hardware.

${ }^{8}$ Deletion of incomplete data points leads to a loss of information. Imputation methods, reviewed by Kofman and Sharpe (2003), could increase the efficiency of the estimator. Since only $11.4 \%$ of the data points for which monthly returns are observed are incomplete, we have not pursued the imputation estimator.
} 
There are two sources of multicollinearity related to the valuation ratios. First, their numerators contain accounting information and are updated only quarterly. The denominator is the stock market capitalization and is the same for all ratios. The monthly change in the valuation ratios could be mostly due to price changes, and therefore might be correlated with short-term momentum. Yet the degree of multicollinearity seems to be limited. The strongest correlation between short-term momentum and a valuation ratio is -0.26 . The maximum correlation among the five valuation ratios are is only 0.53 .

\subsection{Univariate analysis}

As a benchmark for the one-month predictive power of the firm characteristics we construct portfolios that are sorted on a single characteristic. At the beginning of each month $t$ we construct a high and a low portfolio, based on sorting of the stocks by each characteristic and buying the top $30 \%$ of the sorted stocks (the high portfolio), while selling the bottom $30 \%$ of the sorted stocks (the low portfolio). The portfolio is either equally weighted or weighted by the respective characteristic. ${ }^{9}$ Next month $(t+1)$ we record the returns of the high and low portfolios.

The resulting returns for each characteristic separately are reported in panel A of Table 3. Although the negative sign for size corroborates the small firm effect, it is not statistically significant. This might be due to the low number of small firms in the MSCI data. Surprising is the low predictive power of all valuation ratios. The strongest predictive variable are the analyst earnings revisionsis $C F Y$ 1. The effect of long-term price momentum ( $R$ \%-12) is significant, while short-term price momentum (R1-6) has low predictive power in this investable universe. It is interesting that the liquidity variables VOL and 52W have positive and significant effects. Most studies (like BCS98) are based on data that include smaller and less liquid companies, and find a negative and significant liquidity effect. Our data includes a majority of big (i.e. more liquid) firms, and this simple univariate analysis shows that liquidity within the liquid companies might have a different effect.

We inspect whether the predictive power of firm characteristics is robust to industry effects. Within each industry we construct equally weighted and characteristic weighted portfolios based on sorting on each characteristic as described in the previous

\footnotetext{
${ }^{9}$ For the characteristic weighted portfolios, the weight of stock $i$ in month $t$ is computed as the absolute value of the respective characteristic (in deviation of its cross sectional average) for stock $i$, divided by the sum of the absolute values of the characteristic for all stocks observed in month $t$.
} 
paragraph. We form an equally weighted composite portfolio that includes returns from the industry portfolios. We also construct a value weighted composite portfolio that includes returns from all characteristic weighted industry portfolios.

Panel B of Table 3 reports the results from these industry neutral portfolios. Most long-short return differences are approximately the same, while the standard deviations are lower due to the increased diversification. The valuation ratios have higher $t$-statistics than in panel $\mathrm{A}$ of Table 3 . The ratios $C P$ and $E P$ now have significant effects on expected returns. ${ }^{10}$

\section{Results}

We estimate the general specification (5) and several restricted versions, and investigate the predictive power of individual effects, industry effects, time effects and firm characteristics. We also analyze the interaction across these variables and their combined effects on expected stock returns.

\subsection{Individual effects and time effects}

In Table 4 we rank various models on the Schwartz criterion $(S C)$. These models have industry specific coefficients $\beta_{\ell}$ and differ with respect to whether the time effects are missing $\left(\lambda_{\ell t}=0\right)$, pooled over industries $\left(\lambda_{\ell t}=\lambda_{t}\right)$ or industry specific $\left(\lambda_{\ell t}\right)$; and to whether the intercept is pooled $(\mu)$, industry specific $\left(\tau_{\ell}\right)$ or firm specific $\left(\mu_{i}\right)$. For monthly returns the Schwartz criterion always prefers a model without individual effects (i.e. a model with industry specific or pooled intercepts) to the same model with individual effects.

The estimates of the individual effects contain huge positive and negative outliers. The 5\% largest outliers (in absolute value) correspond to companies for which only few observations are available. We therefore repeated the model selection after excluding all firms with less than 60 observations, which reduces the number of firms to 652 . Nevertheless, the bottom panel of Table 4 shows that the ranking of the models is the

\footnotetext{
${ }^{10}$ We investigated the power of monthly firm characteristics to forecast cumulative returns over three and six months. Using three and six month returns instead of monthly returns we repeated the analysis that is shown in Table 3 . In general the $t$-statistics are similar. In case of three month horizon the earnings momentum $C F Y 1$ has predictive power only in industry neutral portfolios, while $R 7$-12, $V O L$ and $52 \mathrm{~W}$ are always powerful predictors. In case of six month horizon the shortterm momentum $R 1-6$ has predictive power only in industry neutral portfolios, while $V O L$ and 52W are always powerful predictors.
} 
same. The $S C$ again prefers the models without individual effects. Individual effects do not seem to improve the cross-sectional fit sufficiently to justify the inclusion of such a large number of parameters.

Repeating the model selection with three- and six-months cumulative returns as the dependent variable, we come to the same conclusion. ${ }^{11}$ The results in Table 4 show that the models without individual effects have the lowest $S C{ }^{12}$

For the time effects the Schwartz criterion always prefers the model with pooled time effects $\lambda_{t}$ to the same model with industry specific time effects $\lambda_{\ell t}$, or compared to the same model without any time effects $\left(\lambda_{\ell t}=0\right)$. This finding is robust to the forecasting horizon and to the exclusion of firms with less than 60 observations. ${ }^{13}$

\subsection{Firm characteristics}

Tables 5, 6 and 7 report the pooled estimates of $\beta$ for different models using as dependent variable either one-, three- or six-month returns, respectively. The models differ again in the structure of the intercepts $\mu_{i}$ and $\lambda_{t}$. Based on the model selection analysis, the preferred model has a pooled time effect and no individual effects. The other columns in tables 5, 6 and 7 are included to examine the robustness of the relation between returns and firm characteristics.

For the monthly returns Table 5 shows that the effects of size $(M V)$ and cash flowto-price $(C P)$ are always significant, independent of the specification of the intercepts. The size effect is now significant, in contrast to the univariate analysis in Table 3 . In models without individual effects dividend-to-price $(D P)$ and volume (VOL) are also significant and have the same signs as in the univariate portfolio strategies. Even the standard errors of the effects are very similar.

The five valuation ratios are always jointly significant. Their estimated coefficients have the correct signs. Since the estimates have reasonably small standard errors, multicollinearity does not seem to be a problem. As in the univariate analysis shortterm momentum $(R 1-6)$ is never significant. Contrary to the univariate analysis in

\footnotetext{
${ }^{11}$ Excluding all firms with less than 60 observations for the six-months returns reduces the number of firms in the panel to 370 . This is a peculiarity in the data, because 277 firms are observed in the last 66 months only.

12 The only exception is the case of industry specific time effects, all firms included and six month returns, when a model with individual effects is preferred to the same model without individual effects. The model is, however, still ranked worse than the model with a pooled time effect.

13 These findings are confirmed by the $S C$-ranking of models with pooled coefficients $\left(\beta_{\ell}=\beta\right)$, and with the same structure of intercepts and time effects as the models in Table 4 (not reported here).
} 
Table 3, earnings momentum (CFY1) and long-term momentum (R7-12) are not always significant in a multivariate approach.

Although individual effects did not seem important, they make a difference to the parameter estimates for some of the characteristics. The size effect is much more pronounced in models with unrestricted $\mu_{i}$. The dividend-to-price effect completely disappears and even obtains the opposite sign. A similar sign change occurs for the long-term volume, which becomes significantly negative as we would expect from the literature on liquidity. The Hausman test, reported in Table 5, indicates that the two sets of parameters are indeed significantly different if individual effects $\mu_{i}$ are included. Not surprisingly, the $t$-statistics for the differences between the individual elements of $\beta$ are especially large for $M V, D P$ and $52 W$. The momentum variables are not affected by the inclusion of individual effects. This result is consistent with Jegadeesh and Titman (2002) who also find that cross-sectional differences in expected return cannot explain profits from momentum strategies.

The model with individual effects itself is practically useless for forecasting purposes, since the individual effects are poorly estimated for most firms. But even though we cannot really estimate the individual effects themselves, the Hausman test indicates that there is a substantial cross-sectional variation in $\mu_{i}$. We interpret the differences in $\beta$ estimates as evidence that some important explanatory variables are still missing. Identifying these variables will not alleviate cross-sectional asset pricing puzzles. For example, the results show that the size effect will become more pronounced once we know what firm characteristics can explain the currently unobserved heterogeneity.

The difference between the estimates of $\beta$ with and without individual effects is a function of the covariance between $\mu_{i}$ and the individual means $\bar{x}_{i}$ of the characteristics,

$$
\operatorname{plim} \hat{\beta}_{P}=\operatorname{plim} \hat{\beta}_{I}+V_{X X}^{-1} V_{X \mu}
$$

where $\hat{\beta}_{P}$ is the pooled estimator, $\hat{\beta}_{I}$ is the individual effects estimator of $\beta, V_{X X}=$ $\operatorname{plim} \frac{1}{N T} \sum_{i} \sum_{t}\left(x_{i t}-\overline{\bar{x}}\right)\left(x_{i t}-\overline{\bar{x}}\right)^{\prime}$ and $V_{X \mu}=\operatorname{plim} \frac{1}{N} \sum_{i}\left(\bar{x}_{i}-\overline{\bar{x}}\right)\left(\bar{x}_{i}-\overline{\bar{x}}\right)^{\prime}$. When we observe that the size effect is more negative for $\hat{\beta}_{I}$, this implies that most likely there is a positive covariance between $M V$ and $\mu_{i}$. Big firms, which have been big during the entire sample period, do not perform much worse than small firms, that have been small during the entire sample period. Firms that were big for a long time, but have fallen in size, perform very well. What matters for the size effect is how a firm ranks 
both with respect to the other firms as well as compared to its own average size.

Tables 6 and 7 report the estimates of $\beta$ for models with three and six month returns as the dependent variable. The estimates for size, the valuation ratios and liquidity are almost the same as for the monthly returns. Even the respective standard errors are comparable. This implies that these characteristics are persistent over time. The relative size, value and liquidity indicators of a firm do not change much from month to month.

Valuation ratios are more important for forecasting of three and six month returns because their numerators are announced quarterly. The coefficients of the long-term price momentum $R$ \%-12 and earnings revisions $C F Y 1$ are now insignificant, implying that analysts forecasts are short-sighted, consistent with the findings of Chan et al. (1996). The six month price momentum $R 1-6$ is significant in all models that forecast six month returns, consistent with Rouwenhorst (1998).

\subsection{Industry effects}

In this section we consider the pooling hypotheses $\tau_{\ell}=\tau$, and $\beta_{\ell}=\beta$, i.e. whether the firm characteristics have the same effect in all industries. For all models without individual effects in Table 5 we estimated a version with industry specific coefficients $\beta_{\ell}$. We formally test whether coefficients are industry specific or can be pooled. The overall null hypothesis is that $\beta_{\ell}=\beta$ for all industries and all characteristics. The test is based on the following version of the general model in equation (5)

$$
y_{i t}=\lambda_{t}+\sum_{\ell=1}^{L} D_{i \ell}\left(\tau_{\ell}+x_{i t}^{\prime} \beta_{\ell}\right)+e_{i t} .
$$

The robust Wald statistic for the 242 restrictions in the null hypothesis is 963.6, rejecting it at any reasonable significance level.

For a more detailed analysis of the cause for the rejection we test whether each firm characteristic has the same coefficients across industries. Table 8 reports the test statistics of the null hypothesis $\beta_{j \ell}=\beta_{j}$ for each characteristic $j$ separately. For monthly returns the null hypothesis is rejected at the $5 \%$ significance level in all model specifications and for all characteristics with exception of DP, CFY1, R7-12 and $52 W$. Rejections of the null hypothesis for other characteristics are not robust to alternative specifications of the time effects.

For the models that forecast three and six month returns the null hypothesis $\beta_{j \ell}=\beta_{j}$ is rejected for all models and characteristics. If the forecasting horizon 
increases, the heterogeneity across industries is more pronounced, resulting in model coefficients that do vary across industries.

As an illustration of the formal tests, Figures 1 and 2 show the resulting industry specific coefficients and $t$-statistics for the industry specific intercepts and five characteristics estimated with the models from Table 8 . The coefficients and $t$-statistics for the other firm characteristics have a similar pattern. The coefficient estimates do not depend much on the specification of the time effects. Only industry specific time effects sometimes lead to higher or lower $t$-statistics for some of the characteristics, as shown by the third bars in Figure 2. Both coefficients and $t$-statistics are very different across industries, distinct outliers are the $5^{\text {th }}$ industry (Commercial) and the $16^{\text {th }}$ industry (Semiconductors). The most extreme outlier is the $18^{\text {th }}$ industry (Data Processing), but this could be due to the low number of firms belonging to that industry. Coefficients and $t$-statistics also vary a lot across some industries with many companies.

\section{Portfolio management implications}

So far we reported on the statical significance of various firm characteristics and industry effects. More relevant is the comparison of univariate and multivariate models in terms of expected returns and risk. To investigate the portfolio management implications of the multivariate models, we consider the time series returns for a number of long-short portfolios. The portfolios are based on three models of interest: a model with pooled coefficients and time effects $\left(\beta, \tau_{\ell}, \lambda_{t}\right)$, a model with industry specific coefficients $\left(\beta_{\ell}, \tau_{\ell}, \lambda_{t}\right)$, and an industry neutral model $\left(\beta_{\ell}, \lambda_{\ell t}\right)$. For each model we construct the fitted values

$$
\hat{y}_{i t}=\sum_{\ell=1}^{L} D_{i \ell}\left(\hat{\tau}_{\ell}+x_{i t}^{\prime} \hat{\beta}_{\ell}\right) .
$$

Each period $t$ the expected returns for the next one, three and six months $\hat{y}_{i t}$ are sorted in a decreasing order. We construct both equally weighted and value weighted portfolios. For the equally weighted portfolios we allocate the top (bottom) $30 \%$ of the sorted stocks to a long (short) portfolio with equal weights. For the value weighted portfolios, the long (short) portfolio contains the best (worst) stocks in proportion to their market value with the total portfolio market value adding up to $30 \%$ of the total market value in the respective month. The number of stocks in the 
value weighted portfolio can therefore differ from the number of stocks in the equally weighted portfolio. Long and short portfolios are constructed each month.

Portfolios based on models that predict cumulative returns for $J$ months follow the overlapping portfolio methodology advocated by Fama (1998). Each month $t$ we predict the returns for the following $J$ months and construct a long and a short portfolio using the procedure described in the previous paragraph. The portfolios are kept for the following $J$ months, and are liquidated at the end of month $t+J$. In month $t+1$ we repeat this procedure and construct new long and short portfolios. These portfolios are liquidated at the end of month $t+J+1$. Therefore, after the start-up period, the aggregate portfolio consists of $J$ overlapping long-short portfolios.

We consider models with pooled time effects $\lambda_{t}$ and models with industry specific time effects $\lambda_{\ell t}$. Portfolio construction differs for both specifications. With pooled time effects $\lambda_{t}$ we sort all stocks. With industry specific time effects we sort stocks separately within each industry and construct industry long-short portfolios. An aggregate portfolio is constructed by adding all industry specific long-short portfolios. For an equally weighted aggregate portfolio the industry returns are aggregated and weighted by the number of stocks in the industry. For a value weighted aggregate portfolio the industry returns are weighted proportionally to the market value of each industry. The aggregate portfolio is industry neutral. Stock picking is active only within industries.

Table 9 shows that the average returns of the long-short portfolios are significantly positive at the $1 \%$ significance level for all models and forecasting horizons. All return differences are also larger than the ones for the univariate portfolios in Table 3. Combining different firm characteristics enhances the predictive power. For all forecasting horizons, long-short portfolios with pooled slopes $\left(\beta, \tau_{\ell}, \lambda_{t}\right)$ generate lower returns and are more risky than portfolios based on the model with industry specific slopes $\left(\beta_{\ell}, \tau_{\ell}, \lambda_{t}\right)$. Also the ratio of average return to the standard deviation is lowest for the portfolios with a pooled $\beta$. The industry neutral portfolio (based on the model $\left.\left(\beta_{\ell}, \lambda_{\ell t}\right)\right)$ has a lower average return for the long portfolio and a higher average return for the short portfolio. Due to increased diversification, the forced industry neutrality also leads to portfolios with much lower variances. The unrestricted portfolios (with pooled $\beta$ ) involve considerable industry bets. In some periods the highest (lowest) expected returns are concentrated in specific industries.

As a next step we analyze the portfolio turnover. The lower the turnover, the lower the transaction costs of a trading strategy. Since explanatory variables vary 
slowly through time or are time-invariant (industry dummies), expected returns are persistent, leading to portfolios that remain fairly stable from month to month. The left panel of Table 10 reports the transition frequencies of stocks going from one portfolio to another in case of monthly forecasting. For the strategies that select stocks from the complete universe, $83 \%$ of the stocks that are in the long portfolio in month $t$ remain there in month $t+1$, while $81 \%$ of the stocks that are in the short portfolio in month $t$ remain there in month $t+1$. On the other hand the industry neutral portfolios (based on the model $\left(\beta_{\ell}, \lambda_{\ell t}\right)$ ) are less stable. The best stocks within an industry change more rapidly than the overall best stocks, partially due to the constant industry intercepts which give some industries a permanent expected advantage over other industries. In total $30 \%$ of the stocks from the neutral portfolio are equally re-distributed to the long and short portfolios. New stocks are equally distributed among the long, the neutral and the short portfolio.

The middle and right panels of Table 10 report the transition frequencies of stocks going from one portfolio to another in case of three and six month forecasting, respectively. The only difference compared to monthly forecasting is the sharply reduced turnover - for example the persistence of the long portfolio increases from $83 \%$ to $94 \%$ when the forecasting horizon grows from one to three months. Longer forecasting horizons do not deteriorate returns and simultaneously drastically decrease portfolio turnover.

Finally we analyze the portfolio risk exposure and run performance attribution regressions of the long-short portfolio returns on the value weighted market portfolio, the Fama-French factors size and value $(S M B$ and $H M L)$, and the momentum factor $U M D .{ }^{14}$ The upper panel of Table 11 reports results for portfolios based on models that predict monthly returns. The coefficients and their significance are similar across models. The portfolios have moderate exposure to the market index and momentum and have virtually no exposure to $H M L$, consistent with the insignificant coefficients of $B P$ in Table 5. The exposure to $S M B$ is high, consistent with the high predictive power of $M V$ documented in Table 5. The performance regressions have a significant positive alpha intercept in all cases, regardless of the included risk factors. ${ }^{15}$ The

\footnotetext{
14 Data for these factors are obtained from the Fama-French database maintained by Kenneth French at the Tuck School of Business at Dartmouth: http://mba.tuck.dartmouth.edu/pages/faculty/ken.french/data_library.html

15 The intercepts have high absolute values (they are measured in percentage points and all entries in Table 11 are on a monthly basis), but this result should be interpreted with some caution since it is based on in-sample forecasting without explicit accounting for transaction costs.
} 
model with industry specific coefficients $\left(\beta_{\ell}, \tau_{\ell}, \lambda_{t}\right)$ has higher alpha's than the other two models $\left(\beta, \tau_{\ell}, \lambda_{t}\right.$ and $\left.\beta_{\ell}, \lambda_{\ell t}\right)$, while the risk exposure of all models is very similar. The value weighted portfolios generate lower abnormal returns than the equally weighted ones. This could be related to the estimation of the model, since all panels have been estimated with equal weights for all stocks in the sample.

The three panels of Table 11 show that portfolio risk exposure is robust to the forecasting horizon. The abnormal returns slightly decrease when the forecasting horizon increases, but remain significant and higher than one percentage point per month. The model with industry specific coefficients $\left(\beta_{\ell}, \tau_{\ell}, \lambda_{t}\right)$ has higher abnormal returns than the other models, and in case of six month forecasting it has the lowest risk exposure.

\section{Conclusion}

We use a panel model data to explain the cross-section of individual stock returns. Our models incorporate industry specific slope coefficients, individual effects and time effects. Inference is robust to cross-sectional and time series correlation. Combining firm characteristics enhances the predictive power. Size, cash flow-to-price and liquidity are the most powerful predictors, followed by price momentum and earnings revisions. Individual stock effects seem to be related to size and liquidity, while time effects are significant and can be pooled over industries. The industry effects are important and can be captured by industry specific coefficients and intercepts that enable within industry predictions. The results are robust to the forecasting horizon.

Simulations of long-short portfolio strategies result in portfolios with low turnover and substantial abnormal returns, and with moderate exposure to market risk and momentum, but significant exposure to size. The risk exposure is robust to the forecasting horizon. Longer forecasting horizons drastically reduce the portfolio turnover, do not deteriorate returns, and change only marginally the risk exposure. Some portfolios are characterized by high and significant abnormal returns, very low turnover and very low risk exposure.

In the paper we emphasized specification issues of the panel. Ultimately the predictive implications of the model should be subjected to an out-of-sample test. A precise out-of-sample analysis of the performance of various portfolio strategies is outside the scope of the present paper. Since we selected firm characteristics that 
previous literature have identified as significant predictors in univariate or bivariate portfolio strategies, we know that the variables in our panel have predictive power. But this predictive power was established in very much the same sample period as we have used to develop our multivariate model. For a real out-of-sample test we would like to use truely out-of-sample data, and also optimise the portfolio strategies, using adequate risk controls.

\section{References}

Baca, S.P., L.P. Garbe and R.A. Weiss (2000), The Rise of Sector Effects in Major Equity Markets, Financial Analysts Journal 56, 34-40.

Bai, J. and S. Ng (2002), Determining the Number of Factors in Approximate Factor Models, Econometrica 70, 191-221.

Baltagi, B.H. (2001), Econometric Analysis of Panel Data, Wiley, New Jersey.

Bodie, Z., A. Kane, and A. Marcus (2002), Investments, Irwin/McGraw-Hill, New York, $5^{\text {th }}$ ed.

Brennan, M.J., T. Chordia, and A. Subrahmanyam (1998), Alternative Factor Specifications, Security Characteristics and the Cross-Section of Expected Stock Returns, Journal of Financial Economics, 49, 345-373.

Brennan, M.J. and A. Subrahmanyam (1995), Investment Analysis and Price Formation in Security Markets, Journal of Financial Economics, 38, 361-382.

Campbell, J.Y., A.W. Lo, and A.C. MacKinlay (1997), The Econometrics of Financial Markets, Princeton University Press, New Jersey.

Campbell, J.Y. and T. Vuolteenaho (2004), Bad Beta, Good Beta, American Economic Review, forthcoming.

Cavaglia, S., C. Brightman, and M. Aked (2000), The Increasing Importance of Industry Factors, Financial Analysts Journal, 56, 41-54.

Chan, L.K.C., N. Jegadeesh, and J. Lakonishok (1996), Momentum Strategies, Journal of Finance, 51, 1681-1713.

Cochrane, J.H. (2001), Asset Pricing, Princeton University Press, New Jersey.

Conrad, J. and G. Kaul (1998), An Anatomy of Trading Strategies, Review of Financial Studies, 11, 489-520.

Daniel, K. and S. Titman (1997), Evidence on the Characteristics of Cross Sectional Variation in Stock Returns, Journal of Finance, 52, 1-33.

Davis, J.L., E.F. Fama, and K.R. French (2000), Characteristics, Covariances and Average Returns: 1929 to 1997, Journal of Finance, 55, 389-406.

De Bondt, W.F.M. and R.J. Thaler (1985), Does the Stock Market Overreact?, Journal of Finance, 40, 793-805.

Dempsey, S.J., G. Laber, and M.S. Rozeff (1993), Dividend Policies in Practice: Is There an Industry Effect?, Quarterly Journal of Business and Economics, 32, $3-13$. 
Driscoll, J.C. and A.C. Kraay (1998), Consistent Matrix Estimation with Spatially Dependent Panel Data, Review of Economics and Statistics, 80, 549-580.

Fama, E.F. (1998), Market Efficiency, Long-Term Returns, and Behavioral Finance, Journal of Financial Economics, 49, 283-306.

Fama, E.F. and K.R. French (1992), The Cross-Section of Expected Stock Returns, Journal of Finance, 47, 427-465.

Fama, E.F. and K.R. French (1995), Size and Book-to-Market Factors in Earnings and Returns, Journal of Finance, 50, 131-156.

Fama, E.F. and K.R. French (1996), Multifactor Explanations of Asset Pricing Anomalies, Journal of Finance, 51, 55-84.

Fama, E.F. and K.R. French (1997), Industry Costs of Equity, Journal of Financial Economics, 43, 153-193.

Fama, E.F. and J.D. MacBeth (1973), Risk, Return and Equilibrium: Empirical Tests, Journal of Political Economy, 71, 607-636.

Frankel, R. and C.M.C. Lee (1998), Accounting Valuation, Market Expectation, and Cross-Sectional Stock Returns, Journal of Accounting and Economics, 25, 283-319.

Haugen, R.A. and N. Baker (1996), Commonality in the Determinants of Expected Stock Returns, Journal of Financial Economics, 41, 401-439.

Heston, S.L. and K.G. Rouwenhorst (1994), Does Industrial Structure Explain the Benefits of International Diversification, Journal of Financial Economics, 36, 327.

Hodrick, R.J. and Z. Zhang (2001), Evaluating the Specification Errors of Asset Pricing Models, Journal of Financial Economics, 62, 327-376.

Jegadeesh, N. and S. Titman (1993), Returns to Buying Winners and Selling Losers: Implications for Stock Market Efficiency, Journal of Finance, 48, 65-91.

Jegadeesh, N. and S. Titman (2001), Profitability of Momentum Strategies: An Evaluation of Alternative Explanations, Journal of Finance, 56, 699-720.

Jegadeesh, N. and S. Titman (2002), Cross-Sectional and Time Series Determinants of Momentum Returns, Review of Financial Studies, 15, 143-157.

Kofman, P. and I. Sharpe (2003), Using Multiple Imputation in the Analysis of Incomplete Observations in Finance, Journal of Financial Econometrics, 1, 216249.

Koski, J.L. and R. Michaely (2000), Prices, Liquidity and the Information Content of Trades, Review of Financial Studies, 13, 659-696.

Lakonishok, J., A. Shleifer, and R. Vishny (1994), Contrarian Investment, Extrapolation and Risk, Journal of Finance, 49, 1541-1578.

Lewellen, J. (2004), Predicting Returns with Financial Ratios, Journal of Financial Economics, 74, 209-235.

Moskowitz, T.J. and M. Grinblatt (1999), Do Industries Explain Momentum?, Journal of Finance, 54, 1249-1290.

Rosenberg, B., K. Reid, and R. Lanstein (1985), Persuasive Evidence of Market Inefficiency, Journal of Portfolio Management, 11, 9-17. 
Rouwenhorst, K.G. (1998), International Momentum Strategies, Journal of Finance, 53, 267-284.

Stoll, H. (1978), The Pricing of Dealer Services: An Empirical Study of NASDAQ Stocks, Journal of Finance, 33, 1152-1173.

Vuolteenaho, T. (2002), What Drives Firm Level Stock Returns?, Journal of Finance, 57, 233-267.

Wansbeek, T.J. and A. Kapteyn (1989), Estimation of the Error Components Model with Incomplete Panels, Journal of Econometrics, 41, 341-361. 
Table 1: Summary Statistics by Industry

The summary statistics are based on 1144 US firms observed over 199 months from Dec. 1985 until June 2002. The first column reports the MSCI industry classification. The second column describes the industry. The column "All firms" refers to the number of companies per industry in the raw data set. The column "Included firms" reports the number of companies remaining after deletion of missing or incomplete data points. The fifth column reports the number of data points per industry. The last four columns report the average returns $(\bar{R})$ and the standard deviations $(\sigma(R))$ of equally weighted (EW) and value weighted (VW) industry portfolios. Average returns and standard deviations are measured in percentage points per month.

\begin{tabular}{|c|c|c|c|c|c|c|c|c|}
\hline \multirow[b]{2}{*}{ Code } & \multirow[b]{2}{*}{ Industry description } & \multirow{2}{*}{$\begin{array}{r}\text { All } \\
\text { firms }\end{array}$} & \multirow{2}{*}{$\begin{array}{r}\text { Included } \\
\text { firms } \\
\end{array}$} & \multirow{2}{*}{$\begin{array}{r}\text { Data } \\
\text { points }\end{array}$} & \multicolumn{2}{|c|}{ EW port. } & \multicolumn{2}{|c|}{ VW port. } \\
\hline & & & & & $\bar{R}$ & $\sigma(R)$ & $\bar{R}$ & $\sigma(R)$ \\
\hline 1 & Basic Materials & 74 & 70 & 7752 & 1.23 & 5.75 & 1.22 & 5.77 \\
\hline 2 & Automobiles & 26 & 24 & 2402 & 1.38 & 6.94 & 1.31 & 6.77 \\
\hline 3 & Consumer & 60 & 58 & 5578 & 1.29 & 5.73 & 1.29 & 5.71 \\
\hline 4 & Retail & 97 & 89 & 7066 & 1.57 & 6.97 & 1.55 & 6.82 \\
\hline 5 & Commercial & 35 & 33 & 1545 & 1.22 & 7.67 & 1.11 & 7.33 \\
\hline 6 & Food and Consumer & 72 & 68 & 7300 & 1.75 & 4.79 & 1.70 & 4.74 \\
\hline 7 & Specialty & 10 & 9 & 1347 & 1.20 & 5.90 & 1.20 & 5.89 \\
\hline 8 & Services & 34 & 32 & 2449 & 1.58 & 5.89 & 1.57 & 5.73 \\
\hline 9 & Health Care & 118 & 108 & 7794 & 1.70 & 6.22 & 1.69 & 5.84 \\
\hline 10 & Oil and Gas & 58 & 53 & 4851 & 1.32 & 7.35 & 1.29 & 7.05 \\
\hline 11 & Banking and Insurance & 114 & 103 & 6710 & 1.80 & 5.69 & 1.76 & 5.74 \\
\hline 12 & Diversified Financials & 77 & 68 & 3833 & 1.48 & 5.68 & 1.54 & 5.75 \\
\hline 13 & Capital Goods & 38 & 34 & 3592 & 1.35 & 5.89 & 1.34 & 5.75 \\
\hline 14 & Machinery-Diversified & 56 & 50 & 5036 & 1.48 & 6.05 & 1.46 & 5.98 \\
\hline 15 & Technology Hardware & 218 & 211 & 12806 & 1.48 & 9.48 & 1.43 & 9.24 \\
\hline 16 & Semiconductors & 15 & 15 & 910 & 2.71 & 17.27 & 2.74 & 17.30 \\
\hline 17 & Computer Services & 10 & 10 & 776 & 1.57 & 8.93 & 1.55 & 8.55 \\
\hline 18 & Data Processing & 9 & 9 & 605 & 2.12 & 6.86 & 2.06 & 6.70 \\
\hline 19 & Telecom & 30 & 19 & 1475 & 0.94 & 7.18 & 0.99 & 6.44 \\
\hline 20 & Utilities & 60 & 51 & 6326 & 1.10 & 4.31 & 1.09 & 4.36 \\
\hline 21 & Power Producers & 4 & 4 & 275 & 0.32 & 11.66 & 0.32 & 11.55 \\
\hline 22 & Transport & 28 & 26 & 3054 & 1.39 & 6.28 & 1.34 & 6.21 \\
\hline
\end{tabular}


Table 2: Summary Statistics of All Firm Characteristics

Panel A reports descriptive statistics of the raw data set. Panel B reports descriptive statistics for the subset of complete data points, and after all valuation ratios were trimmed to the lower and upper $1 \%$ tail of the distribution. A data point is considered to be complete if all variables are available for that particular data point. Panel A is based on 1243 US firms observed over 199 months from Dec. 1985 until June 2002, while panel B is based on a subset of 1144 firms over the same period.

The first column reports the names of the variables: monthly return $(R E T)$, log of the market capitalization $(M V)$, book-to-price $(B P)$, cash flow-to-price $(C P)$, dividend-to-price $(D P)$, earningsto-price $(E P)$, sales-to-price $(S P)$, analyst earnings revisions $(C F Y 1)$, short-term momentum $(R 1-6)$, long-term momentum ( $R$ 7-12), log of the monthly volume $(V O L)$ and log of the average volume over the last 52 weeks $(52 W)$. Returns are measured in percentage points. The variables $R 1-6$ and $R 7-12$ are cumulative six-month returns. The other columns report descriptive statistics of the firm characteristics.

\begin{tabular}{|c|c|c|c|c|c|c|c|}
\hline Variable & Average & $\begin{array}{l}\text { Standard } \\
\text { deviation }\end{array}$ & Minimum & $\begin{array}{r}1^{\text {st }} \\
\text { percentile }\end{array}$ & Median & $\begin{array}{r}99^{t h} \\
\text { percentile }\end{array}$ & Maximum \\
\hline \multicolumn{8}{|c|}{ A - All companies, raw data } \\
\hline$R E T$ & 1.28 & 14.38 & -96.55 & -37.04 & 1.08 & 43.02 & 640.74 \\
\hline$M V$ & 7.88 & 1.54 & 0.92 & 4.53 & 7.91 & 11.63 & 13.31 \\
\hline$B P$ & 0.52 & 0.96 & -46.39 & -0.22 & 0.43 & 2.31 & 112.08 \\
\hline$C P$ & 0.34 & 42.90 & -31.10 & -0.36 & 0.09 & 0.67 & 8337.01 \\
\hline$D P$ & 0.02 & 0.06 & 0.00 & 0.00 & 0.01 & 0.10 & 4.30 \\
\hline$E P$ & 0.00 & 0.83 & -120.00 & -0.93 & 0.05 & 0.20 & 2.88 \\
\hline$S P$ & 1.56 & 4.47 & 0.00 & 0.03 & 0.88 & 10.99 & 918.27 \\
\hline$C F Y 1$ & -0.08 & 0.75 & -1.00 & -1.00 & 0.00 & 1.00 & 1.00 \\
\hline$R 1-6$ & 7.61 & 35.83 & -98.60 & -66.67 & 5.81 & 118.92 & 1813.73 \\
\hline$R 7-12$ & 8.12 & 37.64 & -96.43 & -63.34 & 5.65 & 126.14 & 1597.39 \\
\hline$V O L$ & 16.22 & 1.53 & 2.30 & 12.57 & 16.18 & 20.13 & 22.40 \\
\hline $52 W$ & 13.15 & 1.52 & 0 & 9.71 & 13.10 & 17.00 & 18.46 \\
\hline \multicolumn{8}{|c|}{ B - Complete data, trimmed valuation ratios } \\
\hline$R E T$ & 1.32 & 14.31 & -96.55 & -36.36 & 1.10 & 42.86 & 640.74 \\
\hline$M V$ & 7.93 & 1.53 & 1.49 & 4.65 & 7.96 & 11.67 & 13.31 \\
\hline$B P$ & 0.49 & 0.37 & -0.15 & -0.15 & 0.41 & 2.14 & 2.14 \\
\hline$C P$ & 0.11 & 0.12 & -0.33 & -0.33 & 0.09 & 0.63 & 0.63 \\
\hline$D P$ & 0.02 & 0.02 & 0.00 & 0.00 & 0.01 & 0.09 & 0.09 \\
\hline$E P$ & 0.03 & 0.11 & -0.72 & -0.72 & 0.05 & 0.19 & 0.19 \\
\hline$S P$ & 1.36 & 1.52 & 0.03 & 0.03 & 0.87 & 9.45 & 9.45 \\
\hline$C F Y 1$ & -0.07 & 0.75 & -1.00 & -1.00 & 0.00 & 1.00 & 1.00 \\
\hline$R 1-6$ & 7.95 & 34.95 & -96.83 & -64.74 & 5.95 & 119.85 & 985.96 \\
\hline$R 7-12$ & 8.44 & 37.00 & -96.43 & -62.50 & 5.96 & 126.12 & 1597.39 \\
\hline$V O L$ & 16.27 & 1.51 & 2.30 & 12.79 & 16.22 & 20.25 & 22.40 \\
\hline $52 W$ & 13.22 & 1.45 & 2.15 & 10.01 & 13.14 & 17.20 & 18.46 \\
\hline
\end{tabular}


Table 3: Average Returns from Characteristic Sorted Portfolios

The table reports the average returns of high and low portfolios based on sorting of all stocks by each characteristic, and buying the top $30 \%$ of the sorted stocks (the high portfolio), while selling the bottom $30 \%$ of the sorted stocks (the low portfolio). Each month we observe the returns of the high and low portfolios, constructed in the previous month. The first four columns report average returns for equally weighted high and low portfolios based on sorting on a specific characteristic, the standard deviation $\left(s_{(H-L)}\right)$ of the respective high minus low portfolio, and the $t$-statistics for testing the equality of the mean returns of the high and low portfolios. The same results for characteristic weighted portfolios are reported in the last four columns. The characteristic weighted portfolios are constructed in the same way as value weighted portfolios. The $t$-statistics are adjusted for autocorrelation. Panel A reports results for simple high minus low portfolios while panel B reports results for industry neutral portfolios. Portfolios are first constructed within each industry as described above and then aggregated with weights proportional either to the number of firms in the industry or to the market value of the industry.

\begin{tabular}{|c|c|c|c|c|c|c|c|c|}
\hline \multirow[b]{2}{*}{ Variable } & \multicolumn{4}{|c|}{ Equally weighted } & \multicolumn{4}{|c|}{ Characteristic weighted } \\
\hline & Low & High & $s_{(H-L)}$ & $t$-stat & Low & High & $s_{(H-L)}$ & $t$-stat \\
\hline \multicolumn{9}{|c|}{ A - Simple portfolios } \\
\hline$M V$ & 1.63 & 1.33 & 3.99 & -1.08 & 1.61 & 1.33 & 3.85 & -1.05 \\
\hline$B P$ & 1.42 & 1.65 & 3.85 & 0.67 & 1.45 & 1.70 & 3.83 & 0.74 \\
\hline$C P$ & 1.15 & 1.66 & 4.85 & 1.49 & 1.30 & 1.76 & 5.33 & 1.22 \\
\hline$D P$ & 1.49 & 1.53 & 5.15 & 0.11 & 1.45 & 1.50 & 5.25 & 0.12 \\
\hline$E P$ & 1.38 & 1.64 & 4.78 & 0.76 & 1.59 & 1.68 & 7.39 & 0.17 \\
\hline$S P$ & 1.25 & 1.70 & 4.55 & 1.06 & 1.26 & 1.80 & 4.27 & 1.35 \\
\hline$C F Y 1$ & 1.19 & 1.77 & 2.39 & 3.43 & 1.19 & 1.76 & 2.59 & 3.08 \\
\hline$R 1-6$ & 1.44 & 1.44 & 5.71 & 0.01 & 1.26 & 1.65 & 7.20 & 0.77 \\
\hline$R 7-12$ & 1.12 & 1.88 & 3.87 & 2.79 & 1.18 & 2.10 & 5.14 & 2.53 \\
\hline$V O L$ & 1.08 & 1.74 & 2.98 & 2.54 & 1.09 & 1.76 & 3.02 & 2.51 \\
\hline $52 W$ & 1.17 & 1.77 & 2.99 & 2.28 & 1.18 & 1.79 & 3.05 & 2.25 \\
\hline \multicolumn{9}{|c|}{ B - Industry neutral portfolios } \\
\hline$M V$ & 1.46 & 1.33 & 3.17 & -0.56 & 1.50 & 1.35 & 3.11 & -0.69 \\
\hline$B P$ & 1.33 & 1.55 & 2.30 & 1.11 & 1.40 & 1.62 & 2.70 & 1.19 \\
\hline$C P$ & 1.19 & 1.69 & 2.25 & 2.63 & 1.34 & 1.84 & 3.14 & 2.22 \\
\hline$D P$ & 1.39 & 1.58 & 2.53 & 1.09 & 1.43 & 1.54 & 2.49 & 0.66 \\
\hline$E P$ & 1.27 & 1.66 & 2.35 & 2.39 & 1.52 & 1.69 & 4.07 & 0.71 \\
\hline$S P$ & 1.32 & 1.51 & 2.80 & 0.77 & 1.37 & 1.67 & 3.50 & 0.96 \\
\hline$C F Y 1$ & 1.20 & 1.72 & 1.63 & 4.49 & 1.23 & 1.77 & 1.70 & 4.52 \\
\hline$R 1-6$ & 1.39 & 1.46 & 3.37 & 0.27 & 1.42 & 1.65 & 4.39 & 0.74 \\
\hline$R 7-12$ & 1.17 & 1.69 & 2.32 & 3.16 & 1.22 & 1.94 & 3.13 & 3.23 \\
\hline$V O L$ & 1.13 & 1.62 & 2.27 & 2.59 & 1.15 & 1.73 & 2.39 & 2.92 \\
\hline $52 W$ & 1.19 & 1.63 & 2.27 & 2.29 & 1.21 & 1.76 & 2.40 & 2.68 \\
\hline
\end{tabular}


Table 4: Model Selection

The table reports OLS estimation results for various restricted versions of the panel data model

$$
y_{i t}=\mu_{i}+\sum_{\ell=1}^{L} D_{i \ell}\left(\lambda_{\ell t}+x_{i t}^{\prime} \beta_{\ell}\right)+e_{i t},
$$

with returns $y_{i t}$ measured over different horizons. All models have industry specific coefficients $\beta_{\ell}$. The results are based on 1144 US firms observed over 199 months from Dec. 1985 until June 2002. The first two columns indicate the restrictions on the intercepts $\mu_{i}$ and $\lambda_{\ell t}$. The intercepts $\mu_{i}$ are either not included $\left(\mu_{i}=0\right)$, pooled $\left(\mu_{i}=\mu\right)$, industry specific $\left(\mu_{i}=\sum_{\ell=1}^{L} D_{i \ell} \tau_{\ell}\right)$, or firm specific $\left(\mu_{i}\right)$. The time effects $\lambda_{\ell t}$ are either not included $\left(\lambda_{\ell t}=0\right)$, pooled $\left(\lambda_{\ell t}=\lambda_{t}\right)$, or industry specific $\left(\lambda_{\ell t}\right)$. The total number of parameters is given as $k$; the $R^{2}$ is computed as one minus the ratio of the residual sum of squares to the total sum of squares of returns in deviation of the average return over all observations; $S C$ denotes the Schwartz information criterion defined in equation (17). The upper panels are based on all complete data points. In the lower panels all firms with less than 60 observations are excluded. The first lines of each subpanel show the respective numbers of firms $N$ and data points $n$. Excluding all firms with less than 60 observations for the six-months returns reduces the number of firms in the panel to 370 . This is a peculiarity in the data, because 277 firms are observed in the last 66 months only.

\begin{tabular}{|c|c|c|c|c|c|c|c|c|}
\hline & & \multicolumn{3}{|c|}{ One month } & \multicolumn{2}{|c|}{ Three months } & \multicolumn{2}{|c|}{ Six months } \\
\hline \multirow[t]{3}{*}{$\mu$} & $\lambda$ & $k$ & $R^{2}$ & $S C$ & $R^{2}$ & $S C$ & $R^{2}$ & $S C$ \\
\hline & & \multicolumn{3}{|c|}{$N=1,144$} & \multicolumn{2}{|c|}{$N=1,139$} & \multicolumn{2}{|c|}{$N=1,136$} \\
\hline & & \multicolumn{3}{|c|}{$n=93,482$} & \multicolumn{2}{|c|}{$n=91,664$} & \multicolumn{2}{|c|}{$n=88,915$} \\
\hline$\mu_{i}$ & $\lambda_{\ell t}$ & 5522 & 0.318 & 5.597 & 0.372 & 6.715 & 0.410 & 7.381 \\
\hline 0 & $\lambda_{\ell t}$ & 4380 & 0.258 & 5.496 & 0.306 & 6.675 & 0.294 & 7.418 \\
\hline$\mu_{i}$ & 0 & 1363 & 0.044 & 5.445 & 0.113 & 6.567 & 0.199 & 7.189 \\
\hline$\tau_{\ell}$ & $\lambda_{t}$ & 418 & 0.152 & 5.212 & 0.164 & 6.394 & 0.156 & 7.123 \\
\hline$\mu$ & $\lambda_{t}$ & 397 & 0.151 & 5.211 & 0.161 & 6.394 & 0.150 & 7.127 \\
\hline \multirow[t]{3}{*}{$\tau_{\ell}$} & 0 & 220 & 0.016 & 5.337 & 0.040 & 6.507 & 0.071 & 7.194 \\
\hline & & \multicolumn{3}{|c|}{$N=652$} & \multicolumn{2}{|c|}{$N=640$} & \multicolumn{2}{|c|}{$N=370$} \\
\hline & & \multicolumn{3}{|c|}{$n=79,247$} & \multicolumn{2}{|c|}{$n=77,319$} & \multicolumn{2}{|c|}{$n=59,321$} \\
\hline$\mu_{i}$ & $\lambda_{\ell t}$ & 4842 & 0.331 & 5.271 & 0.373 & 6.387 & 0.407 & 6.891 \\
\hline 0 & $\lambda_{\ell t}$ & 4402 & 0.318 & 5.201 & 0.334 & 6.353 & 0.369 & 6.887 \\
\hline$\mu_{i}$ & 0 & 872 & 0.033 & 5.087 & 0.091 & 6.200 & 0.126 & 6.577 \\
\hline$\tau_{\ell}$ & $\lambda_{t}$ & 418 & 0.174 & 4.868 & 0.197 & 6.013 & 0.215 & 6.440 \\
\hline$\mu$ & $\lambda_{t}$ & 397 & 0.172 & 4.866 & 0.195 & 6.014 & 0.210 & 6.443 \\
\hline$\tau_{\ell}$ & 0 & 220 & 0.017 & 5.013 & 0.048 & 6.155 & 0.081 & 6.562 \\
\hline
\end{tabular}


Table 5: Pooled Parameter Estimates - One Month Returns

The table reports estimation results for the pooled coefficient model

$$
y_{i t}=\mu_{i}+\sum_{\ell=1}^{L} D_{i \ell} \lambda_{\ell t}+x_{i t}^{\prime} \beta+e_{i t}
$$

under different assumptions about the individual and time effects. The variable $M V$ is the log of the market capitalization, measured in billions of dollars; $B P, C P, D P, E P$ and $S P$ are the valuation ratios book-to-price, cash flow-to-price, dividends-to-price, earnings-to-price, and sales-to-price, respectively; $C F Y 1$ is the analyst earnings revisions; $R 1-6$ and $R 7-12$ are short-term and long-term price momentum, respectively; $V O L$ and $52 W$ are logs of the previous month turnover and the average turnover from the preceding 52 weeks, respectively. Each column contains model coefficients and the respective standard errors in parentheses. To correct for scale, all entries for $R 1-6$ and $R^{\gamma}$-12 are multiplied by six. The symbol * (**) means that the respective coefficient is significant at the $5 \%(1 \%)$ level. The column $\left(\beta, \tau_{\ell}\right)$ relates to a model with industry intercepts $\left(\mu_{i}=\tau_{\ell}, \lambda_{\ell t}=0\right)$. The column $\left(\beta, \tau_{\ell}, \lambda_{t}\right)$ refers to pooled time effects and industry intercepts $\tau_{\ell}\left(\mu_{i}=0, \tau_{\ell}, \lambda_{\ell t}=\lambda_{t}\right)$, while the column $\left(\beta, \lambda_{\ell t}\right)$ relates to industry specific time effects $\left(\mu_{i}=0, \tau_{\ell}=0, \lambda_{\ell t}\right)$. The column $\left(\beta, \mu_{i}\right)$ refers to a model with individual intercepts $\left(\mu_{i}, \lambda_{\ell t}=0\right)$. The column $\left(\beta, \mu_{i}, \lambda_{t}\right)$ relates to a model with individual intercepts and pooled time effects $\left(\mu_{i}, \lambda_{\ell t}=\lambda_{t}\right)$. The standard errors have been computed using the robust estimator of covariance matrix in equation (10). The last line reports Hausman statistics that test whether the coefficients of the last two models are significantly different if the individual effects are replaced by industry intercepts. The last column reports $t$-statistics that test whether the coefficients of each characteristic of the models $\left(\beta, \tau_{\ell}, \lambda_{t}\right)$ and $\left(\beta, \mu_{i}, \lambda_{t}\right)$ are significantly different.

\begin{tabular}{|c|c|c|c|c|c|c|}
\hline \multirow[b]{2}{*}{ Variable } & \multicolumn{5}{|c|}{ Models } & \multirow[t]{2}{*}{$t$-stat } \\
\hline & $\beta, \tau_{\ell}$ & $\beta, \tau_{\ell}, \lambda_{t}$ & $\beta, \lambda_{\ell t}$ & $\beta, \mu_{i}$ & $\beta, \mu_{i}, \lambda_{t}$ & \\
\hline$M V$ & $\begin{array}{l}-0.88^{* *} \\
(0.16)\end{array}$ & $\begin{array}{l}-0.80^{* *} \\
(0.13)\end{array}$ & $\begin{array}{l}-0.74^{* *} \\
(0.14)\end{array}$ & $\begin{array}{l}-2.32^{* *} \\
(0.60)\end{array}$ & $\begin{array}{l}-3.36^{* *} \\
(0.31)\end{array}$ & $2.56^{* *}$ \\
\hline$B P$ & $\begin{array}{c}0.15 \\
(0.34)\end{array}$ & $\begin{array}{c}0.14 \\
(0.27)\end{array}$ & $\begin{array}{l}-0.01 \\
(0.22)\end{array}$ & $\begin{array}{c}1.48^{*} \\
(0.68)\end{array}$ & $\begin{array}{c}0.98 \\
(0.52)\end{array}$ & 1.53 \\
\hline$C P$ & $\begin{array}{c}2.18^{*} \\
(0.99)\end{array}$ & $\begin{array}{c}2.11^{* *} \\
(0.77)\end{array}$ & $\begin{array}{c}2.08^{* *} \\
(0.66)\end{array}$ & $\begin{array}{c}1.71^{* *} \\
(0.98)\end{array}$ & $\begin{array}{c}1.68^{*} \\
(0.82)\end{array}$ & 0.44 \\
\hline$D P$ & $\begin{array}{l}26.64^{* *} \\
(12.48)\end{array}$ & $\begin{array}{l}19.40^{* *} \\
(5.18)\end{array}$ & $\begin{array}{l}15.55^{* *} \\
(4.56)\end{array}$ & $\begin{array}{l}-16.26 \\
(14.41)\end{array}$ & $\begin{array}{l}-6.60 \\
(9.64)\end{array}$ & $2.77^{* *}$ \\
\hline$E P$ & $\begin{array}{c}3.30^{* *} \\
(1.59)\end{array}$ & $\begin{array}{c}2.13 \\
(1.32)\end{array}$ & $\begin{array}{c}1.73 \\
(1.17)\end{array}$ & $\begin{array}{l}-0.45 \\
(1.77)\end{array}$ & $\begin{array}{l}-0.69 \\
(1.20)\end{array}$ & -1.51 \\
\hline$S P$ & $\begin{array}{c}0.12 \\
(0.09)\end{array}$ & $\begin{array}{c}0.12 \\
(0.08)\end{array}$ & $\begin{array}{c}0.12 \\
(0.07)\end{array}$ & $\begin{array}{c}0.44 \\
(0.29)\end{array}$ & $\begin{array}{c}0.14 \\
(0.17)\end{array}$ & 1.25 \\
\hline$C F Y 1$ & $\begin{array}{c}0.29 \\
(0.15)\end{array}$ & $\begin{array}{c}0.24^{* *} \\
(0.12)\end{array}$ & $\begin{array}{c}0.28^{* *} \\
(0.08)\end{array}$ & $\begin{array}{c}0.29 \\
(0.15)\end{array}$ & $\begin{array}{l}0.24^{* *} \\
(0.12)\end{array}$ & 0.33 \\
\hline$R 1-6$ & $\begin{array}{l}-0.03 \\
(0.05)\end{array}$ & $\begin{array}{c}0.05 \\
(0.05)\end{array}$ & $\begin{array}{c}0.03 \\
(0.03)\end{array}$ & $\begin{array}{l}-0.05 \\
(0.05)\end{array}$ & $\begin{array}{c}0.04 \\
(0.05)\end{array}$ & 0.01 \\
\hline$R 7-12$ & $\begin{array}{c}0.06 \\
(0.04)\end{array}$ & $\begin{array}{c}0.04 \\
(0.03)\end{array}$ & $\begin{array}{l}0.04^{* *} \\
(0.02)\end{array}$ & $\begin{array}{c}0.07 \\
(0.04)\end{array}$ & $\begin{array}{c}0.08^{* *} \\
(0.02)\end{array}$ & 1.50 \\
\hline$V O L$ & $\begin{array}{l}0.84^{* *} \\
(0.41)\end{array}$ & $\begin{array}{l}0.52^{* *} \\
(0.22)\end{array}$ & $\begin{array}{l}0.55^{* *} \\
(0.19)\end{array}$ & $\begin{array}{c}0.82 \\
(0.43)\end{array}$ & $\begin{array}{c}0.38 \\
(0.22)\end{array}$ & -0.63 \\
\hline $52 W$ & $\begin{array}{l}-0.01 \\
(0.42)\end{array}$ & $\begin{array}{c}0.26 \\
(0.23)\end{array}$ & $\begin{array}{c}0.21 \\
(0.19)\end{array}$ & $\begin{array}{l}-1.04 \\
(0.56)\end{array}$ & $\begin{array}{l}-0.91^{* *} \\
(0.27)\end{array}$ & $-3.61^{* *}$ \\
\hline Hausman & statistics & & & 408.01 & 390.50 & \\
\hline
\end{tabular}


Table 6: Pooled Parameter Estimates - Three Month Returns

The table reports estimation results for the pooled coefficient model

$$
y_{i t}=\mu_{i}+\sum_{\ell=1}^{L} D_{i \ell} \lambda_{\ell t}+x_{i t}^{\prime} \beta+e_{i t}
$$

under different assumptions about the individual and time effects. The returns $y_{i t}$ are measured over three month periods. For further description see the note of Table 5 .

\begin{tabular}{lcccccc}
\hline \multirow{2}{*}{ Variable } & \multicolumn{5}{c}{ Models } & \multirow{2}{*}{-stat } \\
\cline { 2 - 6 } MV & $\beta, \tau_{\ell}$ & $\beta, \tau_{\ell}, \lambda_{t}$ & $\beta, \lambda_{\ell t}$ & $\beta, \mu_{i}$ & $\beta, \mu_{i}, \lambda_{t}$ & \\
& $-2.63^{* *}$ & $-2.34^{* *}$ & $-2.12^{* *}$ & $-6.81^{* *}$ & $-9.75^{* *}$ & $-17.74^{* *}$ \\
BP & $(0.39)$ & $(0.33)$ & $(0.33)$ & $(1.57)$ & $(0.64)$ & \\
& 0.85 & 0.50 & 0.08 & $5.22^{* *}$ & $3.08^{* *}$ & $2.44^{* *}$ \\
CP & $(0.90)$ & $(0.76)$ & $(0.63)$ & $(1.91)$ & $(1.22)$ & \\
& $8.57^{* *}$ & $7.44^{* *}$ & $6.95^{* *}$ & $5.79^{*}$ & $5.52^{* *}$ & -0.56 \\
DP & $(2.81)$ & $(2.19)$ & $(1.94)$ & $(2.54)$ & $(1.55)$ & \\
& $73.02^{* *}$ & $54.90^{* *}$ & $41.08^{* *}$ & -46.60 & -15.24 & $-3.53^{* *}$ \\
EP & $(31.28)$ & $(12.22)$ & $(10.9)$ & $(38.04)$ & $(17.80)$ & \\
& 6.74 & 3.92 & 3.07 & -5.43 & $-5.61^{* *}$ & $-5.43^{* *}$ \\
SP & $(3.96)$ & $(3.63)$ & $(3.03)$ & $(4.41)$ & $(2.61)$ & \\
& 0.23 & 0.26 & 0.26 & 0.98 & 0.21 & 0.15 \\
CFY1 & $(0.24)$ & $(0.22)$ & $(0.21)$ & $(0.61)$ & $(0.27)$ & \\
\multirow{2}{*}{ R1-6 } & 0.23 & 0.08 & 0.29 & 0.18 & -0.04 & -1.38 \\
& $(0.30)$ & $(0.24)$ & $(0.17)$ & $(0.32)$ & $(0.17)$ & \\
R7-12 & 0.12 & $0.25^{* *}$ & $0.21^{* *}$ & 0.02 & $0.19^{* *}$ & 0.01 \\
& $(0.10)$ & $(0.09)$ & $(0.05)$ & $(0.09)$ & $(0.06)$ & \\
VOL & 0.02 & 0.02 & 0.03 & 0.07 & $0.10^{*}$ & 0.71 \\
& $(0.11)$ & $(0.09)$ & $(0.05)$ & $(0.10)$ & $(0.05)$ & \\
52W & 0.37 & -0.09 & 0.02 & 0.16 & $-0.65^{* *}$ & -1.46 \\
& $(0.59)$ & $(0.40)$ & $(0.34)$ & $(0.59)$ & $(0.32)$ & \\
Hausman & $2.25^{* *}$ & $2.49^{* *}$ & $2.28^{* *}$ & -0.89 & $-1.27^{* *}$ & \multirow{2}{*}{$-5.73^{* *}$} \\
\hline \hline
\end{tabular}


Table 7: Pooled Parameter Estimates - Six Month Returns

The table reports estimation results for the pooled coefficient model

$$
y_{i t}=\mu_{i}+\sum_{\ell=1}^{L} D_{i \ell} \lambda_{\ell t}+x_{i t}^{\prime} \beta+e_{i t}
$$

under different assumptions about the individual and time effects. The returns $y_{i t}$ are measured over six month periods. For further description see the note of Table 5 .

\begin{tabular}{|c|c|c|c|c|c|c|}
\hline \multirow[b]{2}{*}{ Variable } & \multicolumn{5}{|c|}{ Models } & \multirow[t]{2}{*}{$t$-stat } \\
\hline & $\beta, \tau_{\ell}$ & $\beta, \tau_{\ell}, \lambda_{t}$ & $\beta, \lambda_{\ell t}$ & $\beta, \mu_{i}$ & $\beta, \mu_{i}, \lambda_{t}$ & \\
\hline$M V$ & $\begin{array}{l}-5.03^{* *} \\
(0.75)\end{array}$ & $\begin{array}{l}-4.74^{* *} \\
(0.67)\end{array}$ & $\begin{array}{l}-4.33^{* *} \\
(0.64)\end{array}$ & $\begin{array}{c}-12.43^{* *} \\
(3.05)\end{array}$ & $\begin{array}{c}-18.52^{* *} \\
(1.05)\end{array}$ & $-16.13^{* *}$ \\
\hline$B P$ & $\begin{array}{c}0.98 \\
(1.58)\end{array}$ & $\begin{array}{c}0.76 \\
(1.33)\end{array}$ & $\begin{array}{c}0.10 \\
(1.10)\end{array}$ & $\begin{array}{l}8.51^{* *} \\
(3.63)\end{array}$ & $\begin{array}{c}5.39^{* *} \\
(1.79)\end{array}$ & 1.92 \\
\hline$C P$ & $\begin{array}{l}16.72^{* *} \\
(5.31)\end{array}$ & $\begin{array}{l}15.20^{* *} \\
(4.05)\end{array}$ & $\begin{array}{l}13.78^{* *} \\
(3.41)\end{array}$ & $\begin{array}{c}10.70^{*} \\
(4.71)\end{array}$ & $\begin{array}{l}10.92^{* *} \\
(2.27)\end{array}$ & -0.56 \\
\hline$D P$ & $\begin{array}{l}137.38^{* *} \\
(54.61)\end{array}$ & $\begin{array}{l}109.82^{* *} \\
(21.64)\end{array}$ & $\begin{array}{l}78.11^{* *} \\
(20.57)\end{array}$ & $\begin{array}{l}-75.90 \\
(56.05)\end{array}$ & $\begin{array}{l}-14.47 \\
(19.13)\end{array}$ & 1.12 \\
\hline$E P$ & $\begin{array}{l}13.32^{* *} \\
(6.23)\end{array}$ & $\begin{array}{c}9.30 \\
(6.06)\end{array}$ & $\begin{array}{c}8.05 \\
(5.13)\end{array}$ & $\begin{array}{r}-12.16 \\
(7.26)\end{array}$ & $\begin{array}{c}-11.04^{* *} \\
(3.17)\end{array}$ & $2.62^{* *}$ \\
\hline$S P$ & $\begin{array}{c}0.49 \\
(0.43)\end{array}$ & $\begin{array}{c}0.58 \\
(0.41)\end{array}$ & $\begin{array}{c}0.55 \\
(0.42)\end{array}$ & $\begin{array}{c}2.25^{*} \\
(1.13)\end{array}$ & $\begin{array}{c}0.86 \\
(0.47)\end{array}$ & 0.41 \\
\hline$C F Y 1$ & $\begin{array}{c}0.73 \\
(0.51)\end{array}$ & $\begin{array}{c}0.35 \\
(0.36)\end{array}$ & $\begin{array}{l}0.82^{* *} \\
(0.28)\end{array}$ & $\begin{array}{c}0.61 \\
(0.53)\end{array}$ & $\begin{array}{c}0.10 \\
(0.19)\end{array}$ & 1.57 \\
\hline$R 1-6$ & $\begin{array}{l}0.40^{* *} \\
(0.16)\end{array}$ & $\begin{array}{c}0.52^{* *} \\
(0.13)\end{array}$ & $\begin{array}{l}0.45^{* *} \\
(0.09)\end{array}$ & $\begin{array}{c}0.21 \\
(0.16)\end{array}$ & $\begin{array}{l}0.38^{* *} \\
(0.06)\end{array}$ & -0.01 \\
\hline$R 7-12$ & $\begin{array}{l}-0.18 \\
(0.17)\end{array}$ & $\begin{array}{l}-0.15 \\
(0.16)\end{array}$ & $\begin{array}{l}-0.13 \\
(0.09)\end{array}$ & $\begin{array}{l}-0.11 \\
(0.14)\end{array}$ & $\begin{array}{c}0.01 \\
(0.06)\end{array}$ & 1.07 \\
\hline$V O L$ & $\begin{array}{c}0.30 \\
(0.84)\end{array}$ & $\begin{array}{c}0.09 \\
(0.66)\end{array}$ & $\begin{array}{c}0.23 \\
(0.59)\end{array}$ & $\begin{array}{l}-0.28 \\
(0.88)\end{array}$ & $\begin{array}{l}-1.07^{* *} \\
(0.37)\end{array}$ & 1.59 \\
\hline $52 W$ & $\begin{array}{l}5.17^{* *} \\
(1.16)\end{array}$ & $\begin{array}{l}5.17^{* *} \\
(0.91)\end{array}$ & $\begin{array}{l}4.81^{* *} \\
(0.86)\end{array}$ & $\begin{array}{l}-1.24 \\
(2.07)\end{array}$ & $\begin{array}{l}-2.76^{* *} \\
(0.68)\end{array}$ & $-8.41^{* *}$ \\
\hline Hausman & statistics & & & 724.39 & 597.69 & \\
\hline
\end{tabular}


Table 8: Tests for Industry Specific Parameters

The table shows Wald-statistics for the null hypothesis $\beta_{\ell}=\beta(\ell=1, \ldots, L)$ for the model

$$
y_{i t}=\mu_{i}+\sum_{\ell=1}^{L} D_{i \ell}\left(\lambda_{\ell t}+x_{i t}^{\prime} \beta_{\ell}\right)+e_{i t}
$$

under different assumptions about the individual and time effects. The alternative is that $\beta$ is different in all industries. The $5 \%$ critical value is 32.67 . The forecasting horizon is one, three and six months. The variable $M V$ is the log of the market capitalization, measured in billions of dollars; $B P, C P, D P, E P$ and $S P$ are the valuation ratios book-to-price, cash flow-to-price, dividends-to-price, earnings-to-price, and sales-to-price, respectively; $C F Y 1$ is the analyst earnings revisions; $R 1-6$ and $R \%-12$ are short-term and long-term price momentum, respectively; $V O L$ and $52 W$ are logs of the previous month turnover and the average turnover from the preceding 52 weeks, respectively. The columns $\left(\beta_{\ell}, \tau_{\ell}\right)$ refer to the fully pooled model $\left(\mu_{i}=\mu, \lambda_{\ell t}=0\right)$. The columns $\left(\beta_{\ell}, \tau_{\ell}, \lambda_{t}\right)$ relate to pooled time effects and industry effects $\tau_{\ell}\left(\mu_{i}=\sum_{\ell=1}^{L} D_{i \ell} \tau_{\ell}, \lambda_{\ell t}=\lambda_{t}\right)$, and the columns $\left(\beta_{\ell}, \lambda_{\ell t}\right)$ refer to industry specific time effects $\left(\mu_{i}=0, \lambda_{\ell t}\right)$. The Wald-statistics are computed using a robust estimator for the covariance matrices of $\hat{\beta}$ and $\hat{\beta}_{\ell}$.

\begin{tabular}{lcccrrrrrr}
\hline & $\beta_{\ell}$ & $\beta_{\ell}$ & $\beta_{\ell}$ & $\beta_{\ell}$ & $\beta_{\ell}$ & $\beta_{\ell}$ & $\beta_{\ell}$ & $\beta_{\ell}$ & $\beta_{\ell}$ \\
Variable & $\tau_{\ell}$ & $\tau_{\ell}, \lambda_{t}$ & $\lambda_{\ell t}$ & \multicolumn{1}{c}{$\tau_{\ell}$} & $\tau_{\ell}, \lambda_{t}$ & \multicolumn{1}{c}{$\lambda_{\ell t}$} & \multicolumn{1}{c}{$\tau_{\ell}$} & \multicolumn{1}{c}{$\tau_{\ell}, \lambda_{t}$} & \multicolumn{1}{c}{$\lambda_{\ell t}$} \\
\hline$M V$ & 94.7 & 93.7 & 73.2 & 101.3 & 99.1 & 114.7 & 104.9 & 102.0 & 133.2 \\
$B P$ & 39.4 & 41.3 & 40.4 & 63.0 & 66.1 & 92.0 & 121.4 & 124.6 & 184.3 \\
$C P$ & 46.5 & 46.5 & 28.2 & 112.8 & 112.8 & 84.4 & 96.8 & 92.8 & 83.0 \\
$D P$ & 15.1 & 18.2 & 25.3 & 34.2 & 38.2 & 43.6 & 98.2 & 112.3 & 88.3 \\
$E P$ & 48.8 & 49.8 & 49.7 & 111.8 & 107.4 & 81.2 & 187.8 & 172.1 & 120.9 \\
$S P$ & 33.2 & 34.1 & 37.9 & 64.0 & 66.3 & 63.6 & 70.5 & 75.3 & 137.9 \\
$C F Y 1$ & 19.7 & 20.5 & 23.7 & 32.9 & 34.2 & 33.9 & 36.2 & 37.9 & 55.2 \\
$R 1-6$ & 46.5 & 47.0 & 33.3 & 98.6 & 100.8 & 81.1 & 68.2 & 67.6 & 94.8 \\
$R 7-12$ & 30.1 & 31.7 & 55.3 & 67.9 & 69.6 & 73.0 & 139.3 & 136.2 & 107.8 \\
VOL & 33.9 & 35.3 & 42.3 & 34.4 & 34.4 & 34.1 & 40.7 & 41.4 & 26.0 \\
52W & 25.4 & 26.1 & 35.7 & 40.1 & 43.0 & 69.1 & 82.5 & 90.2 & 115.6 \\
\hline \hline
\end{tabular}


Table 9: Expected Returns from Portfolio Strategies

The table contains three panels that show portfolio returns based on one, three and six month forecasting. The results are based on 1144 US firms observed over 199 months from Dec. 1985 until June 2002. All entries are on a monthly basis; the entries for returns are in percentage points. For three different specifications of the panel model, each month the stocks are sorted with respect to the expected returns. The $30 \%$ stocks with the highest expected returns are allocated to the long portfolio, while the $30 \%$ stocks with the lowest expected returns to the short portfolio. For the equally weighted portfolio long and short portfolios contain the same number of stocks. For the value weighted portfolios the long portfolio contains the stocks with the highest expected returns making up 30\% of the total market value, and the short portfolio includes $30 \%$ market value with the lowest expected returns. For the model with industry specific time effects $\left(\beta_{\ell}, \lambda_{\ell t}\right)$ the long-short portfolios are first constructed within each industry, and then aggregated with weights proportional either to the number of firms in the industry or to the market value of the industry.

The columns Long and Short contain the average returns of the portfolios over the entire sample period. The standard deviation of the long-short portfolio is denoted as $s_{L-S}$. The $t$-statistic tests the null hypothesis that the long and short portfolios have equal expected returns.

The first line of each panel refers to a model with a pooled time effect and pooled $\beta$ $\left(\beta, \tau_{\ell}, \lambda_{t}\right)$, the second line relates to a model with pooled time effects and industry specific intercepts and coefficients $\left(\beta_{\ell}, \tau_{\ell}, \lambda_{t}\right)$, and the last line contains results for a model with industry specific time effects and coefficients $\left(\beta_{\ell}, \lambda_{\ell t}\right)$.

\begin{tabular}{|c|c|c|c|c|c|c|c|c|}
\hline \multicolumn{9}{|c|}{ One month forecast } \\
\hline \multirow[b]{2}{*}{ Model } & \multicolumn{4}{|c|}{ Equally weighted } & \multicolumn{4}{|c|}{ Value weighted } \\
\hline & Short & Long & $s_{L-S}$ & $t$-stat & Short & Long & $s_{L-S}$ & $t$-stat \\
\hline$\beta, \tau_{\ell}, \lambda_{t}$ & 0.60 & 2.38 & 3.01 & 8.34 & 0.60 & 2.33 & 2.95 & 8.26 \\
\hline$\beta_{\ell}, \tau_{\ell}, \lambda_{t}$ & 0.49 & 2.61 & 2.96 & 10.09 & 0.50 & 2.50 & 2.70 & 10.49 \\
\hline$\beta_{\ell}, \lambda_{\ell t}$ & 0.60 & 2.46 & 2.23 & 11.70 & 0.58 & 2.28 & 2.03 & 11.76 \\
\hline \multicolumn{9}{|c|}{ Three month forecast } \\
\hline & \multicolumn{4}{|c|}{ Equally weighted } & \multicolumn{4}{|c|}{ Value weighted } \\
\hline Model & Short & Long & $s_{L-S}$ & $t$-stat & Short & Long & $s_{L-S}$ & $t$-stat \\
\hline$\beta, \tau_{\ell}, \lambda_{t}$ & 0.77 & 2.41 & 3.03 & 7.58 & 0.75 & 2.36 & 3.01 & 7.48 \\
\hline$\beta_{\ell}, \tau_{\ell}, \lambda_{t}$ & 0.56 & 2.63 & 2.75 & 10.61 & 0.54 & 2.55 & 2.62 & 10.79 \\
\hline$\beta_{\ell}, \lambda_{\ell t}$ & 0.75 & 2.36 & 2.10 & 10.77 & 0.73 & 2.26 & 1.96 & 10.97 \\
\hline \multicolumn{9}{|c|}{ Six month forecast } \\
\hline & \multicolumn{4}{|c|}{ Equally weighted } & \multicolumn{4}{|c|}{ Value weighted } \\
\hline Model & Short & Long & $s_{L-S}$ & $t$-stat & Short & Long & $s_{L-S}$ & $t$-stat \\
\hline$\beta, \tau_{\ell}, \lambda_{t}$ & 0.80 & 2.41 & 2.81 & 7.97 & 0.77 & 2.36 & 2.76 & 7.98 \\
\hline$\beta_{\ell}, \tau_{\ell}, \lambda_{t}$ & 0.63 & 2.63 & 2.65 & 10.53 & 0.62 & 2.56 & 2.59 & 10.40 \\
\hline$\beta_{\ell}, \lambda_{\ell t}$ & 0.80 & 2.36 & 1.95 & 11.17 & 0.78 & 2.25 & 1.84 & 11.13 \\
\hline
\end{tabular}




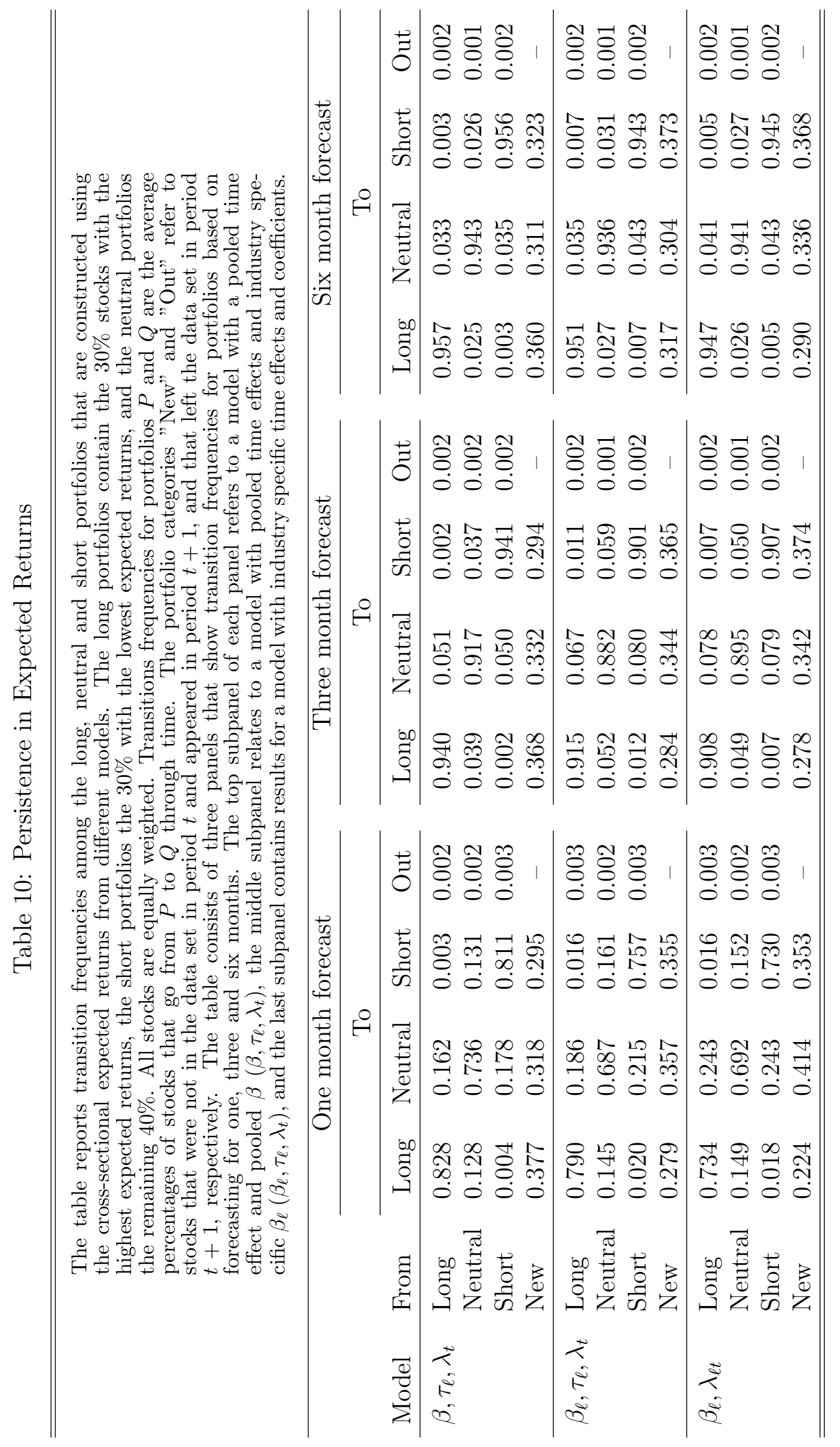


Table 11: Performance Evaluation

The table reports coefficients with autocorrelation robust $t$-statistics in parentheses for the model

$$
R_{t}^{L S}=\alpha+R_{R^{M}}\left(R_{t}^{M}-R_{f t}\right)+S_{S M B} S M B_{t}+H_{H M L} H M L_{t}+U_{U M D} U M D_{t}+\epsilon_{t},
$$

where $R_{t}^{L S}$ is the monthly return of the expected return sorted long-short portfolio, $R^{M}-R_{f}$ is the excess return of the value weighted market index, $S M B$ is the Fama-French "Small minus Big" size factor, $H M L$ is the Fama-French "High minus Low" value factor, and $U M D$ is the "Up minus Down" momentum factor. The entries are on a monthly basis. The intercepts are measured in percentage points. The long-short portfolio returns are constructed using the six strategies shown in Table 9. The first two columns refer to a model with a pooled time effect and pooled $\beta\left(\beta, \tau_{\ell}, \lambda_{t}\right)$, the second two columns relate to a model with pooled time effects and industry specific $\beta_{\ell}\left(\beta_{\ell}, \tau_{\ell}, \lambda_{t}\right)$, and the last two columns refer to a model with industry specific time effects and coefficients $\left(\beta_{\ell}, \lambda_{\ell t}\right)$. The upper panel reports results for portfolios based on monthly forecasting, the middle panel for three-month forecasting, and the lower panel for six-month forecasting. EW stays for equally weighted, and VW - for value weighted.

\begin{tabular}{|c|c|c|c|c|c|c|}
\hline \multirow[b]{2}{*}{ Variable } & \multicolumn{2}{|c|}{$\beta, \tau_{\ell}, \lambda_{t}$} & \multicolumn{2}{|c|}{$\beta_{\ell}, \tau_{\ell}, \lambda_{t}$} & \multicolumn{2}{|c|}{$\beta_{\ell}, \lambda_{\ell t}$} \\
\hline & EW & VW & EW & VW & EW & VW \\
\hline & \multicolumn{6}{|c|}{ One month forecast } \\
\hline$R^{2}$ & 0.27 & 0.30 & 0.14 & 0.11 & 0.30 & 0.33 \\
\hline Intercept & $\begin{array}{c}1.53 \\
(5.69)\end{array}$ & $\begin{array}{c}1.48 \\
(5.90)\end{array}$ & $\begin{array}{c}2.14 \\
(7.61)\end{array}$ & $\begin{array}{c}1.97 \\
(7.94)\end{array}$ & $\begin{array}{c}1.81 \\
(7.57)\end{array}$ & $\begin{array}{c}1.64 \\
(7.90)\end{array}$ \\
\hline$R_{R^{M}}$ & $\begin{array}{c}0.14 \\
(1.90)\end{array}$ & $\begin{array}{c}0.14 \\
(1.87)\end{array}$ & $\begin{array}{c}0.15 \\
(2.27)\end{array}$ & $\begin{array}{c}0.14 \\
(2.26)\end{array}$ & $\begin{array}{c}0.13 \\
(4.24)\end{array}$ & $\begin{array}{c}0.12 \\
(4.42)\end{array}$ \\
\hline$S_{S M B}$ & $\begin{array}{c}0.37 \\
(4.01)\end{array}$ & $\begin{array}{c}0.37 \\
(4.38)\end{array}$ & $\begin{array}{c}0.21 \\
(2.05)\end{array}$ & $\begin{array}{c}0.17 \\
(1.85)\end{array}$ & $\begin{array}{c}0.32 \\
(5.14)\end{array}$ & $\begin{array}{c}0.29 \\
(5.31)\end{array}$ \\
\hline$H_{H M L}$ & $\begin{array}{c}0.11 \\
(1.00)\end{array}$ & $\begin{array}{c}0.08 \\
(0.69)\end{array}$ & $\begin{array}{c}0.19 \\
(1.67)\end{array}$ & $\begin{array}{c}0.20 \\
(1.82)\end{array}$ & $\begin{array}{c}0.09 \\
(1.24)\end{array}$ & $\begin{array}{c}0.05 \\
(0.67)\end{array}$ \\
\hline$U_{U M D}$ & $\begin{array}{c}0.14 \\
(1.79)\end{array}$ & $\begin{array}{c}0.14 \\
(2.05)\end{array}$ & $\begin{array}{l}-0.17 \\
(-2.32)\end{array}$ & $\begin{array}{l}-0.16 \\
(-1.80)\end{array}$ & $\begin{array}{l}-0.06 \\
(-1.00)\end{array}$ & $\begin{array}{c}-0.02 \\
(-0.41)\end{array}$ \\
\hline & \multicolumn{6}{|c|}{ Three month forecast } \\
\hline$R^{2}$ & 0.35 & 0.37 & 0.16 & 0.15 & 0.33 & 0.33 \\
\hline Intercept & $\begin{array}{c}1.43 \\
(5.93)\end{array}$ & $\begin{array}{c}1.38 \\
(6.08)\end{array}$ & $\begin{array}{c}1.97 \\
(7.62)\end{array}$ & $\begin{array}{c}1.87 \\
(10.04)\end{array}$ & $\begin{array}{c}1.50 \\
(7.61)\end{array}$ & $\begin{array}{c}1.40 \\
(7.63)\end{array}$ \\
\hline$R_{R^{M}}$ & $\begin{array}{c}0.11 \\
(1.62)\end{array}$ & $\begin{array}{c}0.11 \\
(1.58)\end{array}$ & $\begin{array}{c}0.15 \\
(2.40)\end{array}$ & $\begin{array}{c}0.14 \\
(3.01)\end{array}$ & $\begin{array}{c}0.12 \\
(4.62)\end{array}$ & $\begin{array}{c}0.10 \\
(3.83)\end{array}$ \\
\hline$S_{S M B}$ & $\begin{array}{c}0.44 \\
(5.49)\end{array}$ & $\begin{array}{c}0.45 \\
(5.77)\end{array}$ & $\begin{array}{c}0.30 \\
(3.60)\end{array}$ & $\begin{array}{c}0.27 \\
(4.91)\end{array}$ & $\begin{array}{c}0.34 \\
(5.68)\end{array}$ & $\begin{array}{c}0.30 \\
(5.09)\end{array}$ \\
\hline$H_{H M L}$ & $\begin{array}{c}0.08 \\
(0.57)\end{array}$ & $\begin{array}{c}0.08 \\
(0.60)\end{array}$ & $\begin{array}{c}0.24 \\
(1.58)\end{array}$ & $\begin{array}{c}0.27 \\
(3.98)\end{array}$ & $\begin{array}{c}0.14 \\
(1.64)\end{array}$ & $\begin{array}{c}0.10 \\
(1.20)\end{array}$ \\
\hline$U_{U M D}$ & $\begin{array}{c}0.13 \\
(2.32)\end{array}$ & $\begin{array}{c}0.15 \\
(2.80)\end{array}$ & $\begin{array}{l}-0.06 \\
(-1.00)\end{array}$ & $\begin{array}{l}-0.03 \\
(-0.71)\end{array}$ & $\begin{array}{l}-0.01 \\
(-0.04)\end{array}$ & $\begin{array}{c}0.04 \\
(1.26)\end{array}$ \\
\hline \multicolumn{7}{|c|}{ Six month forecast } \\
\hline$R^{2}$ & 0.26 & 0.27 & 0.12 & 0.13 & 0.29 & 0.28 \\
\hline Intercept & $\begin{array}{c}1.40 \\
(6.26)\end{array}$ & $\begin{array}{c}1.37 \\
(6.35)\end{array}$ & $\begin{array}{c}1.78 \\
(7.48)\end{array}$ & $\begin{array}{c}1.70 \\
(7.52)\end{array}$ & $\begin{array}{c}1.40 \\
(8.01)\end{array}$ & $\begin{array}{c}1.33 \\
(7.87)\end{array}$ \\
\hline$R_{R^{M}}$ & $\begin{array}{c}0.10 \\
(1.48)\end{array}$ & $\begin{array}{c}0.09 \\
(1.36)\end{array}$ & $\begin{array}{c}0.12 \\
(1.86)\end{array}$ & $\begin{array}{c}0.11 \\
(1.85)\end{array}$ & $\begin{array}{c}0.12 \\
(3.78)\end{array}$ & $\begin{array}{c}0.09 \\
(3.12)\end{array}$ \\
\hline$S_{S M B}$ & $\begin{array}{c}0.34 \\
(4.07)\end{array}$ & $\begin{array}{c}0.34 \\
(4.09)\end{array}$ & $\begin{array}{c}0.24 \\
(2.83)\end{array}$ & $\begin{array}{c}0.21 \\
(2.63)\end{array}$ & $\begin{array}{c}0.24 \\
(4.92)\end{array}$ & $\begin{array}{c}0.26 \\
(4.60)\end{array}$ \\
\hline$H_{H M L}$ & $\begin{array}{c}0.11 \\
(0.68)\end{array}$ & $\begin{array}{c}0.11 \\
(0.73)\end{array}$ & $\begin{array}{c}0.28 \\
(1.59)\end{array}$ & $\begin{array}{c}0.31 \\
(1.73)\end{array}$ & $\begin{array}{c}0.17 \\
(1.73)\end{array}$ & $\begin{array}{c}0.14 \\
(1.48)\end{array}$ \\
\hline$U_{U M D}$ & $\begin{array}{c}0.15 \\
(2.63)\end{array}$ & $\begin{array}{c}0.16 \\
(2.85)\end{array}$ & $\begin{array}{c}0.08 \\
(1.13)\end{array}$ & $\begin{array}{c}0.09 \\
(1.26)\end{array}$ & $\begin{array}{c}0.14 \\
(1.69)\end{array}$ & $\begin{array}{c}0.07 \\
(2.28)\end{array}$ \\
\hline
\end{tabular}




\section{Figure 1: Industry Specific Parameter Estimates}

Each graph in the figure relates to the $j^{\text {th }}$ firm characteristic and shows values of the $j^{\text {th }}$ elements of the vectors $\beta_{\ell}$ for all industries. For each industry the figure shows estimates of $\beta_{\ell}^{j}$ for three different specifications of the model in equation (5). For each graph, the first bar refers to a model with industry intercepts and no time effects $\left(\beta_{\ell}, \tau_{\ell}\right)$. The second bar relates to a model with industry specific intercept and pooled time effects $\left(\beta_{\ell}, \tau_{\ell}, \lambda_{t}\right)$, and the third bar stays for a model with industry specific time effects $\left(\beta_{\ell}, \lambda_{\ell t}\right)$. To be identified the third model $\left(\beta_{\ell}, \lambda_{\ell t}\right)$ cannot contain industry specific intercepts, as Section 2 explains. Therefore only two bars are related to each industry in the first graph that shows industry intercepts. In some graphs industry 21 is omitted, since it contains only four firms and has extreme outliers for most parameter estimates. The numbers on the horizontal axes denote industries according to the MSCI classification in Table 1.
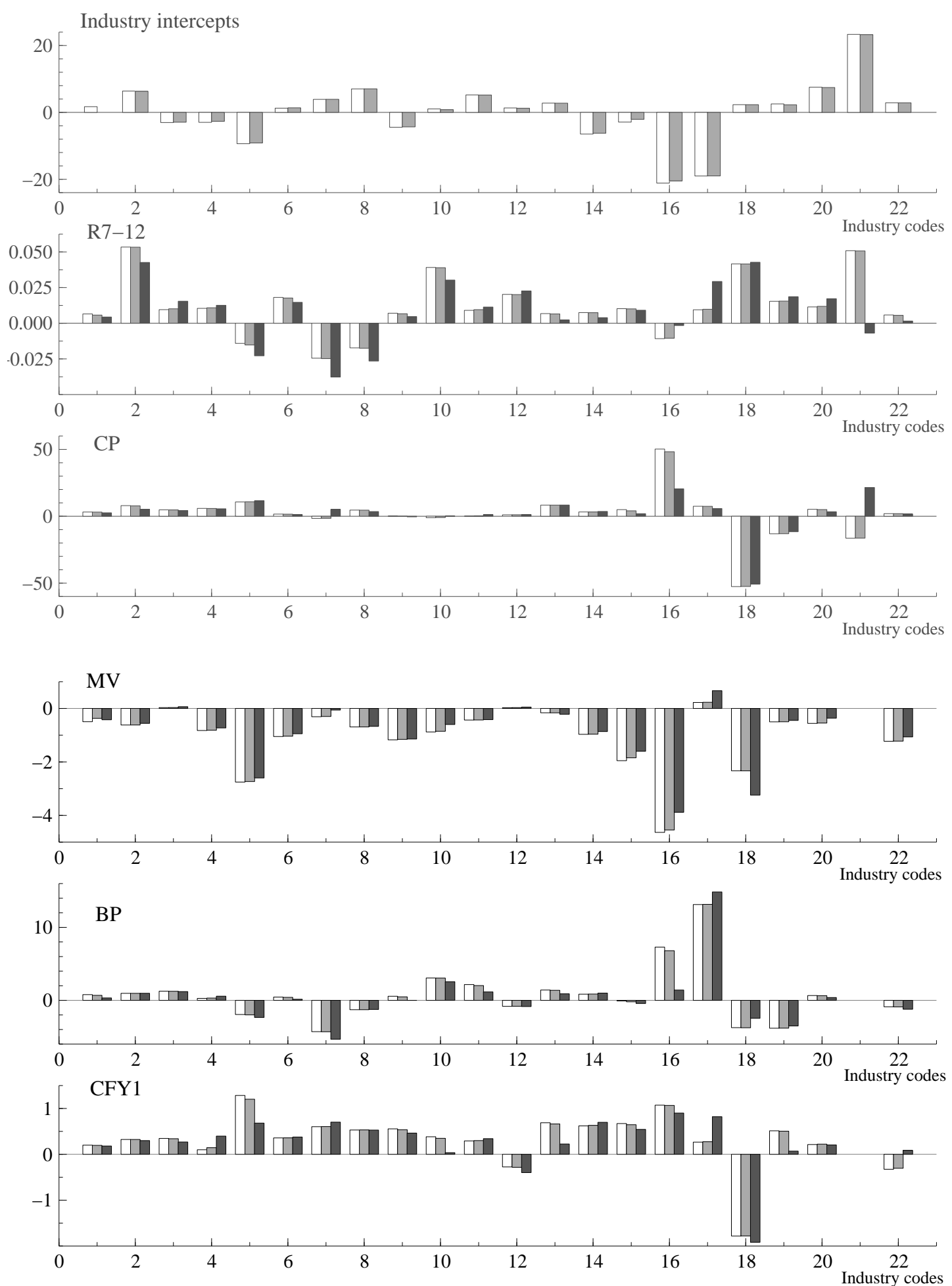
Figure 2: Industry Specific $t$-statistics of Model Coefficients

Each graph in the figure relates to the $j^{\text {th }}$ firm characteristic and shows the values of the $t$-statistics of the $j^{t h}$ elements of the vectors $\beta_{\ell}$ for all industries. For each industry the figure shows the $t$ statistics of the estimated $\beta_{\ell}^{j}$ for three different specifications of the model in equation (5). For each graph, the first bar refers to a model with industry intercepts and no time effects $\left(\beta_{\ell}, \tau_{\ell}\right)$. The second bar relates to a model with industry specific intercept and pooled time effects $\left(\beta_{\ell}, \tau_{\ell}, \lambda_{t}\right)$, and the third bar stays for a model with industry specific time effects $\left(\beta_{\ell}, \lambda_{\ell t}\right)$. To be identified the third model $\left(\beta_{\ell}, \lambda_{\ell t}\right)$ cannot contain industry specific intercepts, as Section 2 explains. Therefore only two bars are related to each industry in the first graph that shows industry intercepts. The numbers on the horizontal axes denote industries according to the MSCI classification in Table 1.
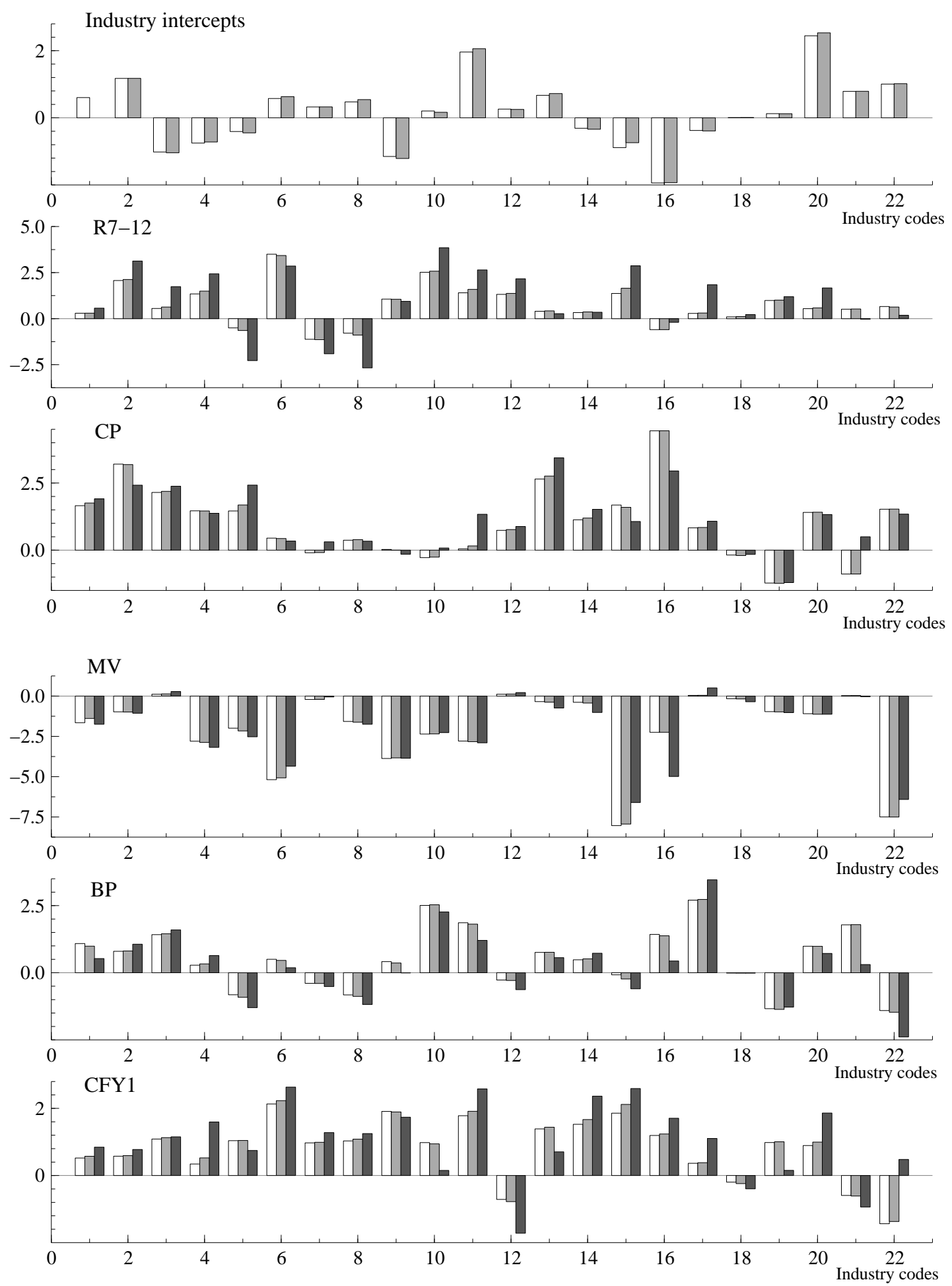